\title{
Analysis of IncRNA-miRNA-mRNA expression pattern in heart tissue after total body radiation in a mouse model
}

\author{
Molykutty J. Aryankalayil ${ }^{1 *} \mathbb{D}$, Shannon Martello ${ }^{1}$, Michelle A. Bylicky', Sunita Chopra', Jared M. May ${ }^{1}$, \\ Aman Shankardass ${ }^{1}$, Laurel MacMillan², Landy Sun², Jaleal Sanjak ${ }^{2}$, Claire Vanpouille-Box ${ }^{3}$, Iris Eke ${ }^{1,4}$ and \\ C. Norman Coleman ${ }^{1,5}$
}

\begin{abstract}
Background: Radiation therapy is integral to effective thoracic cancer treatments, but its application is limited by sensitivity of critical organs such as the heart. The impacts of acute radiation-induced damage and its chronic effects on normal heart cells are highly relevant in radiotherapy with increasing lifespans of patients. Biomarkers for normal tissue damage after radiation exposure, whether accidental or therapeutic, are being studied as indicators of both acute and delayed effects. Recent research has highlighted the potential importance of RNAs, including messenger RNAs (mRNAs), microRNAs (miRNAs), and long non-coding RNAs (IncRNAs) as biomarkers to assess radiation damage. Understanding changes in mRNA and non-coding RNA expression will elucidate biological pathway changes after radiation.
\end{abstract}

Methods: To identify significant expression changes in mRNAs, IncRNAs, and miRNAs, we performed whole transcriptome microarray analysis of mouse heart tissue at $48 \mathrm{~h}$ after whole-body irradiation with 1, 2, 4, 8, and 12 Gray (Gy). We also validated changes in specific IncRNAs through RT-qPCR. Ingenuity Pathway Analysis (IPA) was used to identify pathways associated with gene expression changes.

Results: We observed sustained increases in IncRNAs and mRNAs, across all doses of radiation. Alas2, Aplnr, and Cxc3r1 were the most significantly downregulated mRNAs across all doses. Among the significantly upregulated mRNAs were cell-cycle arrest biomarkers Gdf15, Cdkn1a, and Ckap2. Additionally, IPA identified significant changes in gene expression relevant to senescence, apoptosis, hemoglobin synthesis, inflammation, and metabolism. LncRNAs Abhd110s, Pvt1, Trp53cor1, and Dino showed increased expression with increasing doses of radiation. We did not observe any miRNAs with sustained up- or downregulation across all doses, but miR-149-3p, miR-6538, miR-8101, miR-7118-5p, miR-211-3p, and miR-3960 were significantly upregulated after $12 \mathrm{~Gy}$.

Conclusions: Radiation-induced RNA expression changes may be predictive of normal tissue toxicities and may indicate targetable pathways for radiation countermeasure development and improved radiotherapy treatment plans.

Keywords: Radiation, Biomarkers, Normal tissue injury, miRNA, mRNA, IncRNA, Heart

\footnotetext{
*Correspondence: aryankalayilm@mail.nih.gov

${ }^{1}$ Radiation Oncology Branch, Center for Cancer Research, National

Cancer Institute, National Institutes of Health, 10 Center Drive, Room B3B406, Bethesda, MD 20892, USA

Full list of author information is available at the end of the article
}

\section{Introduction}

Radiotherapy (RT) is a mainstay of cancer treatment as it reduces recurrence, improves survival, and enhances the efficacy of other treatments. Ionizing radiation (IR) exposure, whether from RT, diagnostic imaging, or accidental original author(s) and the source, provide a link to the Creative Commons licence, and indicate if changes were made. The images or other third party material in this article are included in the article's Creative Commons licence, unless indicated otherwise in a credit line to the material. If material is not included in the article's Creative Commons licence and your intended use is not permitted by statutory regulation or exceeds the permitted use, you will need to obtain permission directly from the copyright holder. To view a copy of this licence, visit http://creativecommons.org/licenses/by/4.0/. The Creative Commons Public Domain Dedication waiver (http://creativeco mmons.org/publicdomain/zero/1.0/) applies to the data made available in this article, unless otherwise stated in a credit line to the data. 
sources (e.g., a nuclear disaster), can cause a multitude of side effects, including secondary cancers and other iatrogenic diseases [1-3]. Accidental or radiotherapeutic normal tissue injury can cause many transient or permanent alterations in both cellular and extracellular components within the irradiated field [4]. These are particularly harmful to critical organs such as the heart. Retrospective studies of atomic bomb survivors found evidence that excess relative risk of death due to heart disease increased by $14 \%$ per Gray (Gy) of radiation absorbed, linking radiation exposure with long-term cardiac effects [5-7]. Similarly, liquidators exposed to radiation in the Chernobyl exclusion zone displayed a statistically significant excess relative risk for developing cardiovascular disease [8]. Discovery of organ-specific biomarkers will allow for early treatment prior to clinical manifestations of radiation damage.

In an analysis of breast cancer patients treated with RT, radiation was an independent risk factor for death from cardiovascular disease ten or more years after thoracic radiation [9]. Radiation-induced heart disease (RIHD) is a well-documented side effect of thoracic irradiation during treatment of breast, lung, lymphoma, and other mediastinal tumors [10-13]. Late effects of radiationinduced damage to the heart will become increasingly apparent as the population of long-term cancer survivors continues to increase. By 2022, the U.S. alone will have an estimated 18 million cancer survivors; many of them will have been treated with RT $[14,15]$.

The first clinical symptom of RT-induced damage to the heart manifests as acute pericarditis between 3 and 6 months after irradiation [16]. However, radiationinduced dysfunction of the heart, including coronary artery disease (CAD), myocardial fibrosis, cardiomyopathy, valvular disease, and arrhythmias leading to congestive heart failure may take decades to manifest $[17,18]$. Understanding the molecular mechanism behind RIHD development will help identify efficient prophylactic and mitigative treatments. Furthermore, early detection and prediction of normal tissue injury and cardiotoxicity will facilitate interventions to improve quality of life for RT patients and substantially reduce medical costs related to treatment of secondary diseases.

Radiation-induced DNA damage causes genome-wide transcriptional changes. These changes produce alterations in a wide range of cellular functions from immune response to metabolism $[19,20]$. However, prior attempts to discover markers of radiation injury to the heart have been unsuccessful. In a study of patients undergoing thoracic radiation without chemotherapy, analysis of c-reactive protein, angiogenic, and inflammatory markers in serum indicated no correlation between levels and dose of radiation [19]. Other studies on markers of RIHD have yielded conflicting results, with no clear consensus on the value of troponin or brain natriuretic peptides (BNP) levels [21]. One recent study indicated that peroxisome proliferator activator receptor alpha (Ppara) may be a dose dependent marker for mitochondrial dysfunction and subsequent RIHD [22]. However, further research is necessary to determine the utility of this marker.

The stability and organ specificity of non-coding RNAs make them attractive as diagnostic and therapeutic biomarkers [23, 24]. Several human and mouse heart RNA expression studies have revealed deregulation of lncRNAs in response to heart damage and disease, with over 600 lncRNAs reported as differentially expressed in clinically failing hearts [25-32]. Previous research has highlighted the importance of miRNAs in diseases for multiple cell types, including cardiomyocytes, endothelial cells, smooth muscle cells, and fibroblasts [33-37]. However, there is limited research on understanding their role in normal tissue damage after radiation [38-40]. Our lab and others have identified alterations in lncRNA and miRNA at long and short time points post-radiation both in vivo and in vitro [41-44]. In a previous study, our laboratory demonstrated dose responsive upregulation in whole blood of damage induced noncoding lncRNA (Dino), plasmacytoma variant translocation $1(P v t 1)$ and tumor protein P53 pathway corepressor 1 (Trp53cor1) in a whole-body irradiation mouse model [44]. The results of these studies informed the approach we used in the current investigation.

With cancer and cardiovascular disease as the two leading causes of mortality in the world, understanding the effects of RIHD from RT or accidental exposure will be critical to minimizing health consequences [45]. In this study, we utilized whole transcriptome analysis on mouse heart tissues $48 \mathrm{~h}$ after whole-body doses of $1,2,4,8$, or 12 Gy. Understanding biological pathways that lead to RIHD development will allow for the identification of treatments to improve quality of life for individuals exposed to radiation, either therapeutically or accidentally, and provide diagnostic and/or prognostic markers of damage.

\section{Methods}

Total body irradiation of mice and sample collection

Six- to 8-week old female C57BL/6 J mice were given total-body irradiation (TBI) with X-rays using the Small Animal Radiation Research Platform (SARRP Xstrahl Ltd.). Mice were placed in plastic containers and exposed to a single surface dose of $1,2,4,8$, or 12 Gy at a dose rate of $1.05 \mathrm{~Gy} / \mathrm{min}$. Control mice (0 Gy) were placed in the same type of plastic container and sham irradiated. Three animals per dose were included in the study. Hearts of irradiated and control animals were harvested $48 \mathrm{~h}$ after 
TBI. Organs were snap frozen in liquid nitrogen and stored at $-80{ }^{\circ} \mathrm{C}$ until processed for RNA isolation. All animal experiments were performed at the Department of Pathology at New York University (NYU) Langone Medical Center under an approved IACUC protocol as part of a collaborative study.

\section{RNA isolation}

Samples were bathed in liquid nitrogen and pulverized into a fine powder using a mortar and pestle. Approximately $100 \mu \mathrm{g}$ of powdered sample was lysed with $700 \mu \mathrm{l}$ of QIAzol lysis buffer (Cat \# 79306, QIAGEN) and homogenized by passing the solution through QIAshredder spin columns (Cat \# 79654, QIAGEN). RNA isolation was performed using standard miRNeasy mini kit (Cat \# 217004, QIAGEN) according to the manufacturer's protocol. Quality and quantity of the RNA samples were assessed using a DeNovix DS-11 nanodrop spectrophotometer (DeNovix, DE, US) and Agilent Bioanalyzer with the RNA6000 Nano Lab Chip (Agilent Technologies, Santa Clara, CA).

\section{Microarray analysis}

Microarray analysis was performed for sham animals (0 Gy) and 1 Gy, 2 Gy, 4 Gy, 8 Gy, and 12 Gy irradiated animals. Quality assessments and microarray experiments were completed as previously reported [46]. Samples were hybridized to Agilent Mouse GE $8 \times 60 \mathrm{~K}$ v2 arrays for mRNA expression analysis and to Agilent Mouse miRNA $8 \times 60 \mathrm{~K}$ v21.0 arrays (Design ID 070155) for miRNA expression analysis. Slides were washed and scanned on an Agilent SureScan Microarray Scanner. Expression values were extracted using Agilent Feature Extraction software and data were analyzed with GeneSpring GX software (Agilent Technologies).

\section{Real time RT-qPCR analysis of mRNAs and IncRNAs}

$1000 \mathrm{ng}$ of total RNA was reverse transcribed using RT2 First Strand Synthesis kit (Qiagen, US). Individual RTqPCR reactions using RT2 $\mathrm{qPCR}$ primer assays and RT2 SYBR Green qPCR Master Mix (QIAGEN, US) were performed for the following lncRNAs: Trp53cor1 (Assay ID No. LPM12776A), Dino [47] (FP- GCAATGGTGTGC CTGACTAT; RP- TTCTGGCTTCCCAGAG), Pvt1 (LPM16140A) and Rplpo (assay ID no. PPM03561B) in the $48 \mathrm{~h}$ mouse heart tissue samples. Relative expression was calculated as: $2^{-\mathrm{dCt}}$ where $\mathrm{dCt}=\mathrm{Ct}$ [test gene] $-\mathrm{Ct}$ [Rplp0] [44]. Following qPCR Primer Assay were used for mRNA validation PPM03371A- Ckap-2, PPM05273AAlas2, PPM04436C-Gdf15, PPM02901B-Cdkn1a, PPM03154A-Cx3cr1, and PPM04813A-Aplnr. RplpO was used as the normalizing control in both lncRNA and mRNA PCR assays.

\section{miRNA RT-qPCR}

200 ng of total RNA was used for first-strand cDNA synthesis reactions using miRCURY LNA RT Kit (Cat. No. 339340) according to the manufacturers protocol. Reverse-transcription reaction was done at $42^{\circ}$ for $60 \mathrm{~min}$, followed by an inactivation step at $95^{\circ}$ for 5 min. Quantitative Real-Time PCR was done using individual miRCURY LNA miRNA PCR Assays (Cat. No. 339306) for the following primers (mmu-miR-103a-3p, mmu-miR-149 3p, mmu-miR-211-3p, mmu-miR-3960, mmu-miR-6538, mmu-miR-7118-5p, mmu-miR-8101) to detect differential expression in irradiated vs. control samples. Real time PCR reactions were performed using Applied Biosystems Quant Studio Real-Time PCR machine. PCR steps included initial heat activation at $95^{\circ}$ for 2 min followed by two step cycling: Denaturation at $95^{\circ}$ for $10 \mathrm{~s}$ followed by combined annealing/extension at $56^{\circ}$ for $60 \mathrm{~s}$ for 40 cycles. A melt curve analysis was performed to ensure the specificity of the corresponding RT$\mathrm{qPCR}$ reactions. Fold change $=2^{-\mathrm{ddCt}}$ where $\mathrm{ddCt}=\mathrm{dCt}$ (irradiated) $-\mathrm{dCt}$ (control); $\mathrm{dCt}=\mathrm{Ct}$ (gene) $-\mathrm{Ct}$ (endo control: UniSp6); and $\mathrm{Ct}$ is the threshold cycle number. All assays were performed in triplicates. Statistical significance was calculated using student's unpaired $t$-test.

\section{Statistical analysis}

Analysis of mRNA and miRNA data was performed using $\mathrm{R}$ statistical software and the Bioconductor Linear Model for Microarray Analysis (LIMMA) package in $\mathrm{R}$ [48]. Background correction and normalization were performed in $\mathrm{R}$ using the normal-exponential correction method and quantile normalization between arrays [49]. Only probes with intensities above background on at least one array were kept in the dataset for analysis. Transcripts with multiple probes were averaged such that the final set reflected best estimates of transcript level expression. A linear model was fit to each probe to assess differential expression for pair-wise dose comparisons within the heart-tissue samples. This method employed an empirical Bayes smoothing approach that results in more stable model estimates by using information on variance from the whole probe set, despite the small number of arrays. Models were developed for each of the pair-wise comparisons between each dose $(1,2,4$, 8 , and $12 \mathrm{~Gy}$ ) and the control probes ( $0 \mathrm{~Gy}$ ), and resulting probes were filtered using $\log _{2}$ fold change and adjusted p-value thresholds $\left(\left|\log _{2} \mathrm{FC}\right|>1\right.$, adjusted p-value $\left.<0.05\right)$ [50]. Additionally, a nested interaction model was fit for each probe to examine dose within tissue as a linear (continuous) trend. Each model yielded main effects for the heart tissue and dose within the heart tissue. Probes were filtered using the nested dose coefficients with log fold 
change and adjusted p-value thresholds $\left(\left|\log _{2} \mathrm{FC}\right|>1\right.$, adjusted $\mathrm{p}$-value $<0.05$ ). Finally, gene ontology analysis was utilized to identify affected pathways from the differentially expressed probes.

To identify potential interactions, paired analysis was conducted to evaluate correlative relationships between pairs of differentially expressed mRNA and miRNA probes. mRNA and miRNA probes were paired using shared target transcript Ensembl IDs [51]. Probes that could not be mapped or paired were excluded. Transcripts for miRNA probes were identified using an Agilent microarray gene dataset and the TargetScan database; transcripts for mRNA probes were identified using an Agilent microarray gene dataset [52]. Transcript-miRNA pairs with a TargetScan context ++ score above -1 were excluded. Probe pairs with differentially expressed miRNA and mRNA probes were identified within the heart tissue for continuous dose contrast models. Pearson correlation coefficients of miRNA and mRNA expression across all experiments were calculated and plotted for the differentially expressed probe pairs.

\section{Ingenuity pathway analysis}

Both core and comparison analyses were performed in IPA (QIAGEN Inc., https://www.qiagenbioinformatics. com/products/ingenuitypathway-analysis). Pathways and function terms that satisfied an absolute $\mathrm{z}$-score $>2$ and $\mathrm{p}$-value $<0.01$ were predicted to be altered based on the gene expression data.

\section{Results}

\section{Radiation induces widespread transcriptional changes}

Microarray analysis performed on all mouse heart samples revealed 2041 differentially expressed genes $(|\log 2 \mathrm{FC}|>1$; p-value $<0.05)$ that distinguished unirradiated control samples from samples of at least one dose of TBI mice. Overall, most genes had relatively low to no basal expression in control samples and showed increased expression levels after TBI; however, a cluster of genes showed relatively pronounced high expression in control samples that decreased to low expression after irradiation (Fig. 1A). For each dose, more genes were differentially upregulated than downregulated (Fig. 1B). Across all doses, 99 genes were commonly expressed in response to radiation and $128,55,390,322$, and 316 genes were expressed exclusively after $1,2,4,8$, and 12 Gy of TBI, respectively (Fig. 1C). Additional file 2: Table S1 lists fold changes and $\mathrm{p}$-values of all differentially expressed genes by dose. While there was no systemic dose-response in terms of the number of genes expressed, we did observe more differentially expressed genes in the higher doses $(4,8,12$ Gy) than in the lower doses (1, 2 Gy). When the dose response of each gene was analyzed by fitting a linear model to each probe, 596 probes were found to have significant dose-responsive up- or down-regulation across all doses; here we present the 20 most upregulated and downregulated genes (Additional file 3: Table S2). Cdkn1a, Ckap2, and Gdf15 were among the top 20 probes with the strongest upward linear trend, and Alas2, $A p \ln r$, and $C \times 3 \mathrm{cr} 1$ were among the top 20 probes with the strongest downward linear trend (Fig. 1D). All six genes have previously been reported in the context of radiation or DNA damage response and fall into three main biological roles: cell cycle arrest, hemoglobin metabolism, and inflammatory response (Table 1). The prior relevant literature on Cdkn1a [53, 54], Gdf15 [55, 56], Ckap2 [57, 58], Alas2 [59, 60], Aplnr [61, 62] and Cx3cr1 [63, 64] are listed in Table 1. We validated the expression of the most significantly upregulated and downregulated mRNAs in our data using RT-qPCR (Additional file 1: Figure S1).

\section{Low basal expression levels of long non-coding RNAs in heart tissue showed increased expression after TBI}

To understand the response of heart-based lncRNAs to TBI, we filtered whole genome microarray data to include only probes that correspond to transcripts of lncRNAs. Of the 87 lncRNA transcripts in the microarray data that passed the background intensity cutoff in at least one condition, 46 were differentially expressed in response to radiation, irrespective of the TBI dose (Fig. 2A). Most lncRNAs showed relatively low expression in unirradiated control samples with increased expression after radiation. More probes showed upregulation than downregulation in all doses except 2 Gy, which had 4 downregulated lncRNAs and 3 upregulated lncRNAs (Fig. 2A, B). Two lncRNAs were significantly altered at all doses after radiation, including: chr10:69819062-69871640_F and chr17:29183003-29217681_R (Trp53cor1-up) (Additional file 4: Table S3) (Fig. 2C). Additional lncRNAs were altered only at specific doses, with $1,1,7,7$, and 10 lncRNAs expressed exclusively in 1, 2, 4, 8, and 12 Gy, respectively (Fig. 2C). Additional file 4: Table S3 lists the fold changes and p-values for the differentially expressed lncRNAs at each dose. Twenty probes showed significant linear upward or downward trends as the dose of TBI increased, demonstrating a linear dose response (Additional file 5: Table S4). Abhd11os, Trp53cor1, Pvt1, and Kalrn were among the most significant annotated lncRNAs that became upregulated as radiation dose increased, while the linc-RAM (Malrn) transcript had the most significant dose-responsive downregulation (Fig. 2D). Trp53cor 1 was the most sensitive to radiation, showing significant increase in the relative intensity in comparison to the unirradiated control even after $1 \mathrm{~Gy}$ of TBI. The basal level expression of Trp53cor 1 lncRNA expression was below detection threshold levels in 


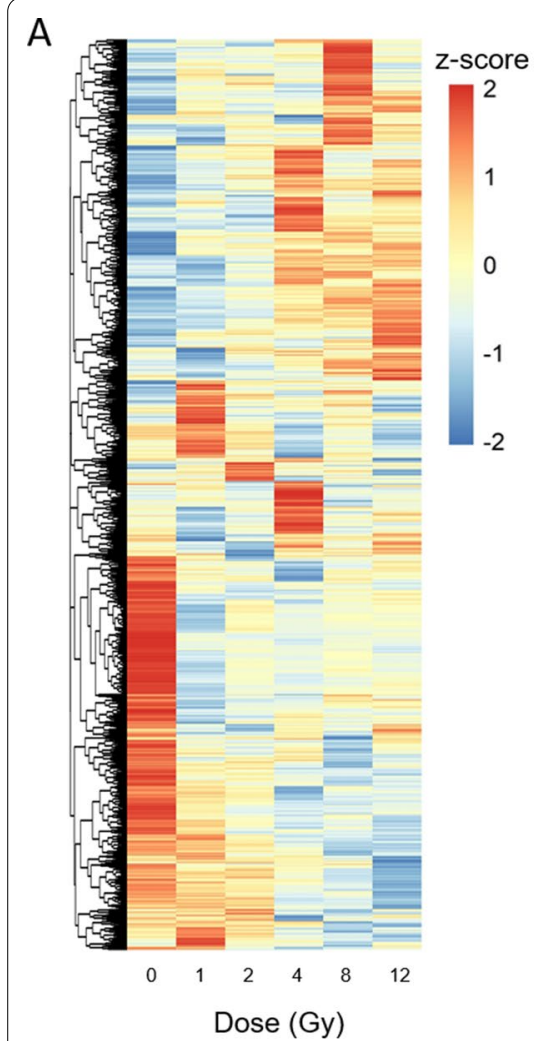

\begin{tabular}{lcc} 
B & & \\
\hline Dose & Upregulated & Downregulated \\
\hline 1 Gy & 92 & 407 \\
2 Gy & 48 & 220 \\
4 Gy & 380 & 633 \\
8 Gy & 402 & 490 \\
12 Gy & 356 & 597 \\
\hline
\end{tabular}
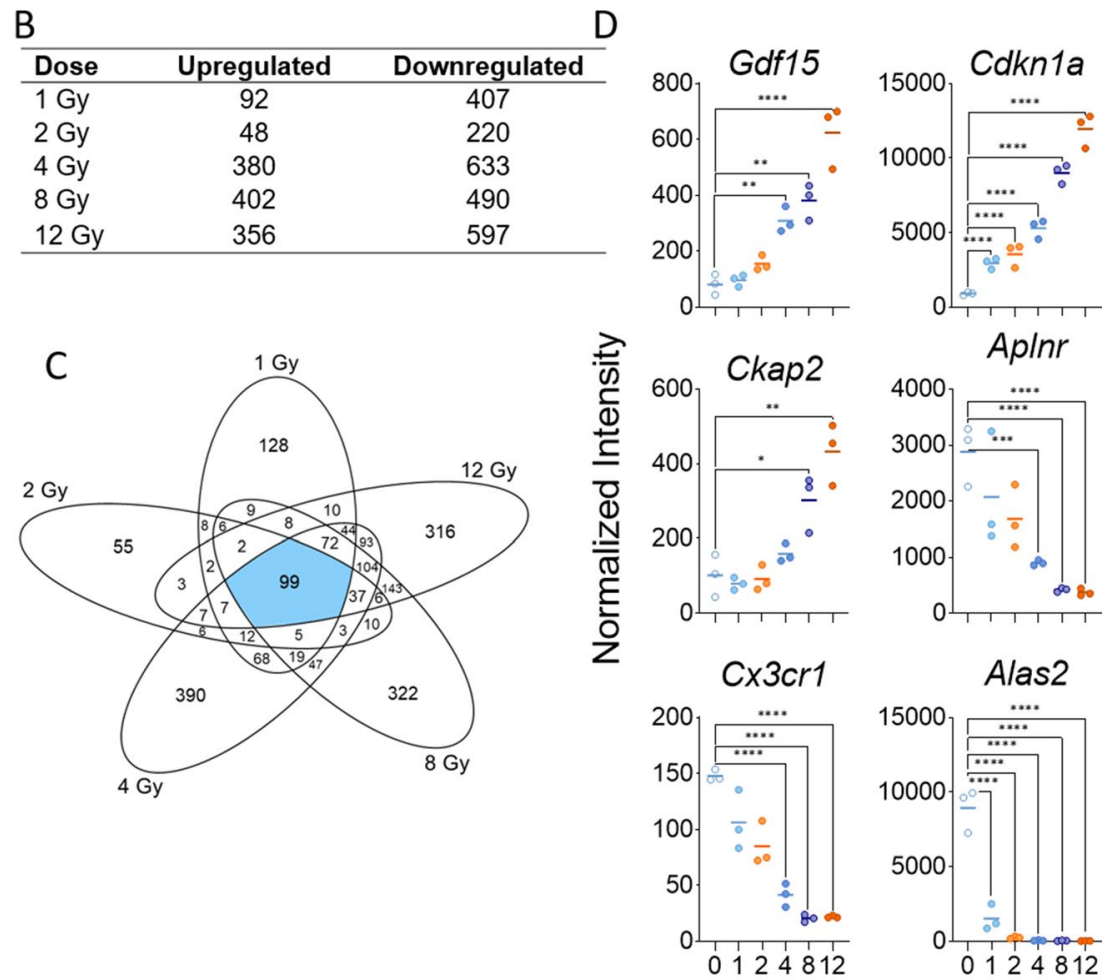

Fig. 1 Radiation-induced gene expression profiles in mouse heart tissue. Whole genome microarray analysis was performed on all samples. A linear model was fit to each probe to evaluate differential expression of irradiated samples compared to controls. Criteria of $\mid \log _{2}$ Fold Change (FC) $\mid>1$ and Benajmini-Hochberg adjusted $(\mathrm{B}-\mathrm{H}) \mathrm{p}$-value $<0.05$ relative to controls were used to determine significance and differential expression. A Heatmap displays expression patterns, represented by z-score, of all differentially expressed mRNAs across all doses and controls. B Venn diagram shows dose distribution and overlap of differentially expressed mRNAs across all doses. C The number of down-regulated versus up-regulated mRNAs at each dose are shown in the table. $\mathbf{D}$ Examples of significant linearly up- and down-regulated mRNAs are shown to display the dose response to radiation in heart tissue samples

Table 1 Biological roles of most significantly dose-responsive mRNAs

\begin{tabular}{|c|c|c|c|}
\hline Gene symbol & Gene name & Biological process involvement & $\begin{array}{l}\text { Previous reports } \\
\text { related to } \\
\text { radiation }\end{array}$ \\
\hline Cdkn1a & Cyclin-dependent kinase inhibitor $1 \mathrm{~A}$ & DNA damage-induced apoptosis; cell cycle arrest & {$[53,54]$} \\
\hline Gdf15 & Growth differentiation factor 15 & Heart-derived hormone; pathogenesis of atherosclerosis & {$[55,56]$} \\
\hline Ckap2 & Cytoskeleton associated protein 2 & Cell cycle arrest; essential for proper chromosome segregation & {$[57,58]$} \\
\hline Alas2 & Aminolevulinic acid synthase 2 , erthyroid & Hemoglobin metabolism pathway; cardiotoxicity & {$[59,60]$} \\
\hline Aplnr & Apelin receptor & $\begin{array}{l}\text { Coordination of monocyte trafficking in hemeostatic and inflam- } \\
\text { matory states }\end{array}$ & {$[61,62]$} \\
\hline $\mathrm{C} \times 3 \mathrm{cr} 1$ & Chemokine (C-X3-C motif) receptor 1 & Chemokine binding; cell adhesion & {$[63,64]$} \\
\hline
\end{tabular}

Genes displayed correspond to the top three most significantly dose-responsive up- and down-regulated mRNAs shown in Fig. 1D. A short-list of biological process involvement and previous reports of involvement in the molecular response to radiation are shown

unirradiated heart tissue. Due to this reason, we used relative intensity to describe expression of Trp53cor 1 after radiation.
In contrast, basal expression of Abhd11os was at a much higher threshold across all doses, including control samples, with significantly higher expression levels 


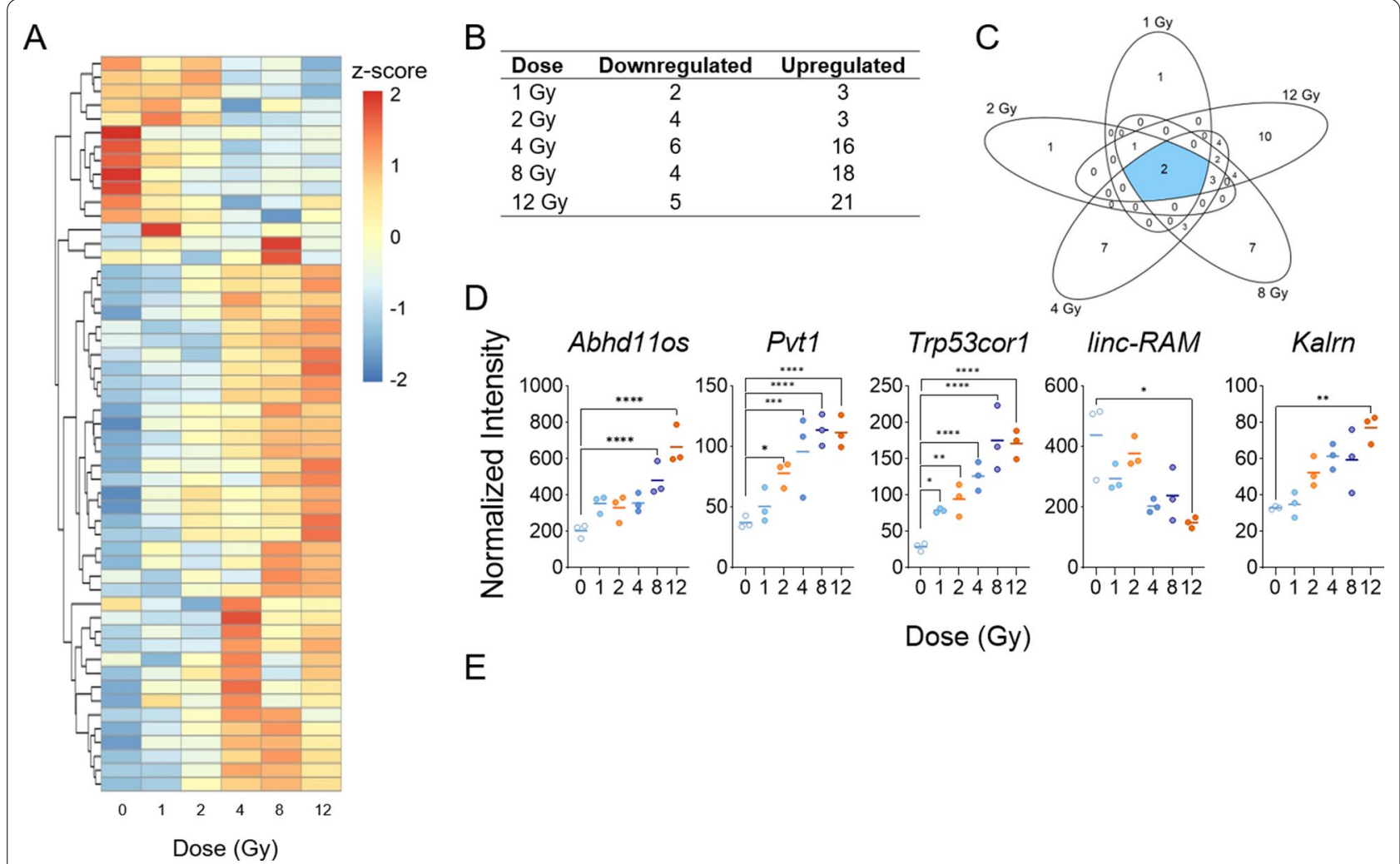

Fig. 2 Radiation-induced long non-coding RNA expression profiles in mouse heart tissue. Whole genome microarray data was filtered to include only probes that correspond to transcripts of IncRNAs. A linear model was fit to each IncRNA probe to assess differential expression of irradiated compared to control samples using criteria of $\left|\log _{2} \mathrm{FC}\right|>2$ and $\mathrm{B}-\mathrm{H}$-value $<0.05$. A Heatmap displays expression patterns, represented by z-score, of all differentially expressed IncRNAs across all doses and controls. B Venn diagram shows dose distribution and overlap of differentially expressed IncRNAs across all doses. C The table shows the number of down- versus up-regulated IncRNAs at each dose. D Examples of significant linearly up- and down-regulated IncRNAs are shown to display the dose response of IncRNAs to radiation in heart tissue samples. E RT-qPCR validation was performed on significantly up-regulated IncRNAs that were previously reported in the blood [44]

after 8 and 12 Gy TBI. Pvt1 showed significance after 2 Gy and Abhd11os showed significance after 8 Gy, while Kalrn and linc-RAM showed significance only after 12 Gy TBI. We confirmed the expression of Dino, Pvt1, and Trp53cor1 in heart samples through RTqPCR (Fig. 2E). In concordance with the microarray data, Trp53cor1 showed very low expression in control samples but significant dose-responsive upregulation after radiation. Pvt1 also showed consistent results with the microarray in terms of the dose response; however, it showed significance in expression change only after 12 Gy TBI. Damage induced noncoding lncRNA (Dino) was not present in our microarray data due to lack of a probe, but prior data from our lab led us to validate its expression in the heart via RT-qPCR. We found that Dino is also significantly expressed in the heart after every dose of TBI. Like Trp53cor1, Dino showed very low expression levels in control samples but increased significantly after radiation (Fig. 2E).

\section{Low dose of total-body irradiation induces the most significant and pronounced changes of microRNA expression in mouse heart tissue}

A separate whole genome microarray analysis of miRNA expression revealed 102 significantly altered miRNAs in mouse heart tissue in response to radiation. Surprisingly, the largest and most significant changes in expression occurred after 1 Gy of TBI, with 86 differentially expressed miRNAs identified at this dose (Fig. 3A). Furthermore, there were no commonly expressed miRNAs across all doses and no miRNAs significantly expressed in 4 or 8 Gy TBI samples (Fig. 3B, C). We did observe significant regulation of miRNAs at 2 and 12 Gy; however, the numbers were relatively low, with 1 and 19 miRNAs in 2 and 12 Gy, respectively. Fold changes and p-values for all significantly altered miRNAs at each dose are listed in Additional file 6: Table S5. Linear trends were fit to all miRNA probes to identify dose response across all doses and found 21 probes that showed significant upward linear trend (Additional file 7: Table S6). No miRNAs 


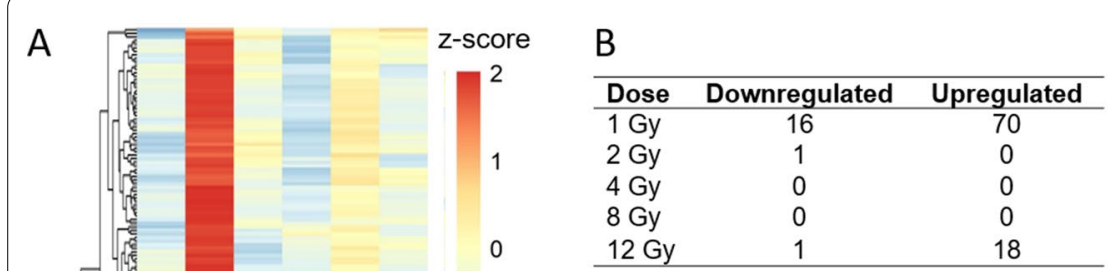

$\mathrm{D}$

miR-149-3p miR-6538
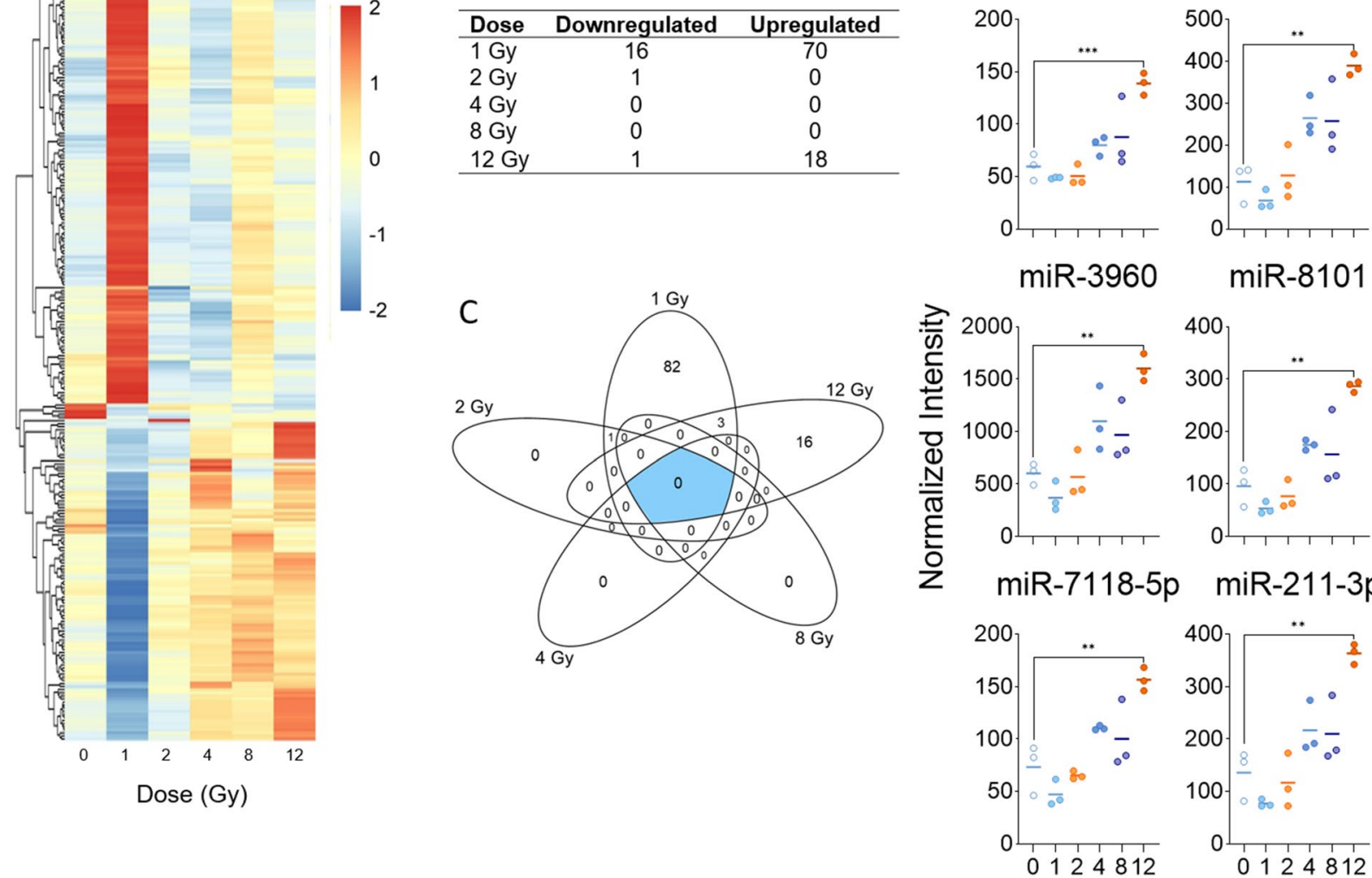

\section{Dose (Gy)}

Fig. 3 Radiation-induced microRNA expression profiles in mouse heart tissue. Microarray analysis was performed for all samples, and a linear model was fit to each miRNA probe to assess differential expression of irradiated samples compared to controls. Criteria of $\left|\log _{2} \mathrm{FC}\right|>2$ and B-H p-value $<0.05$ relative to controls were used to determine significance and differential expression. A Heatmap displays expression patterns, represented by z-score, of all differentially expressed miRNAs across all doses and controls. B Venn diagram shows dose distribution and overlap of differentially expressed miRNAs across all doses. C The number of down-regulated versus up-regulated miRNAs at each dose are shown in the table. D Examples of significant linearly up- and down-regulated miRNAs are shown to display the dose response to radiation in heart tissue samples

showed a significant downward linear trend. Among the top linear probes were miR-149-3p, miR-6538, miR-3960, miR-8101, miR-7118-5p, and miR-211-3p, all of which showed a statistically significant increase in expression only after 12 Gy of TBI (Fig. 3D). We validated expression of miR-149-3p, miR-3960, miR-7118, miR-6538, miR-8101, and miR-103a-3p (Additional file 8: Figure S2). miR-211-3p was below detection using RT-qPCR (data not shown).

\section{Pathway analysis of mRNA targets reveals biological} role of inversely correlated mRNA-miRNA pairs and their potential as part of an integrated TBI response signature Since we are ultimately interested in developing integrated signatures of coding and non-coding RNA response to radiation, we sought to identify potential interactions of the miRNA and mRNA signatures and their biological significance. Using IPA, we first conducted miRNA target filter analysis of the significant differentially expressed miRNAs to identify experimentally verified mRNA targets in our dataset. Canonical pathway analysis of the identified targets revealed significant activation of pathways relevant to cell cycle checkpoint activation and senescence, including p53 signaling and numerous apoptosis signaling pathways, among others (Fig. 4A). Interestingly, most pathways activated across all doses were predicted to have the highest activation after 4 Gy TBI, followed by lower activation in 8 and $12 \mathrm{~Gy}$. One exception to this was the senescence pathway, which showed the lowest activation at $4 \mathrm{~Gy}$. A concurrent higher activation of various apoptosis pathways after 4 Gy TBI may suggest that miRNA-mRNA pairs at this dose exhibit a different response to stress and DNA damage than both lower and higher doses at this time-point after irradiation. Interestingly, analysis of the mRNA targets of the significant miRNAs revealed the strongest activation 
A

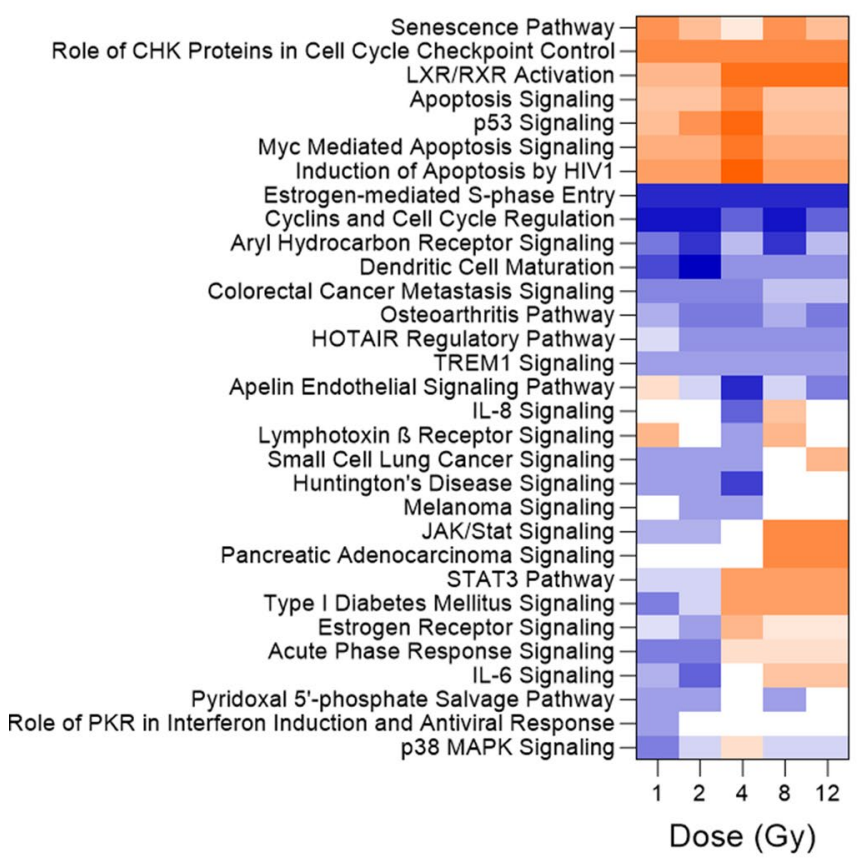

B

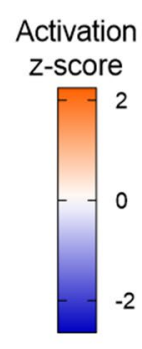

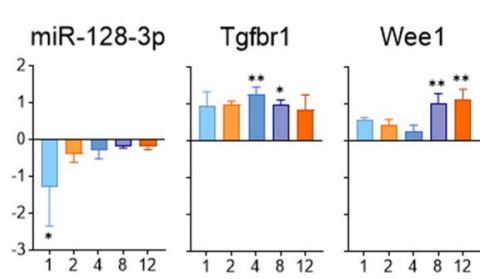

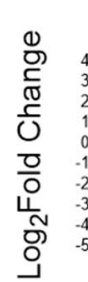

miR-122-5p

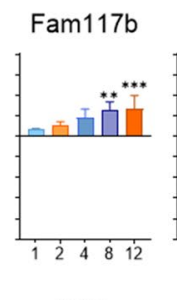

Slc7a11

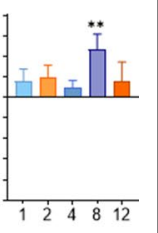

miR-18b-5p

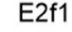

E2f2
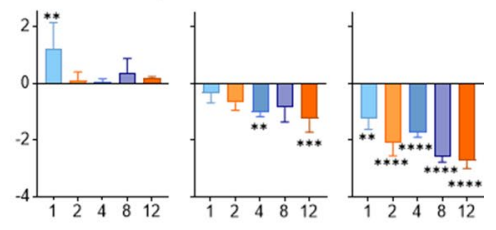

Dose (Gy)

Fig. 4 Significant dysregulation of canonical pathways observed through changes in expression of the mRNA targets of differentially expressed miRNAs. Experimentally verified and differentially expressed mRNA targets of differentially expressed miRNAs were analyzed using IPA to predict effects of miRNA-mRNA pairs on canonical pathways. A Heatmap displays canonical pathways that were predicted to be significantly dysregulated (B-H p-value $<0.01$ across all doses) based upon differentially expressed mRNA targets. A positive $z$-score indicates predicted activation of the pathway based on gene expression and a negative z-score indicates predicted deactivation of the pathway based on gene expression. Pathways are hierarchically clustered by z-score. B Fold changes of inversely correlated miRNA-mRNA target pairs with involvement in the significantly dysregulated pathways. Three miRNAs had two mRNA targets each that were inversely correlated across all doses and significant in at least one condition

and deactivation of pathways after 4 Gy TBI, despite a majority of differential miRNA expression after 1 Gy TBI. Since pathway analyses are based on mRNA rather than miRNA data, it is likely that this observation arises from the more pronounced mRNA expression at $4 \mathrm{~Gy}$ compared to $1 \mathrm{~Gy}$, After pathway analysis, we identified predicted miRNA-mRNA pairs with inverse expression patterns, demonstrating their potential for inclusion in an integrated RNA marker signature to improve clinical decision making. We found three miRNAs that showed significant expression in at least one dose and had predicted targets with inverse expression patterns, each miRNA with two targets. Radiation decreased expression of both miR-128-3p and miR-122-5p relative to control, while their targets-Tgfbr1 and Wee1, and Fam117b and Slc7a11, respectively-showed a statistically significant increase in expression as radiation increased (Fig. 4B). The third miRNA, miR-18-5p, showed increased expression after radiation, most significantly after $1 \mathrm{~Gy}$. Its targets, $E 2 f 1$ and $E 2 f 2$, showed significant down regulation across all doses.

\section{Pathway analysis of all mRNAs predicts activation of immune and cell-cycle related pathways} and deactivation of metabolic pathways after TBI

While understanding the interactions and biological implications of the miRNAs and mRNAs is critical for developing an integrated biomarker signature, we hypothesized that because the relatively low number of differentially expressed miRNAs would limit the number of mRNAs included in the pathway analysis, we could potentially miss genes that play a significant role in pathway regulation. Therefore, we also conducted a canonical pathway analysis using all differentially expressed mRNAs, irrespective of interactions with miRNAs in our dataset. A similar overall pattern of pathway regulation exists between the target mRNAs and target/non-target mRNAs, with significant deactivation of most of the pathways involved (Fig. 5A). Several pathways related to coagulation, including both ex- and intrinsic prothrombin activation and the coagulation system pathway, were downregulated across all doses. Changes in immunerelated pathways were less consistent in terms of 


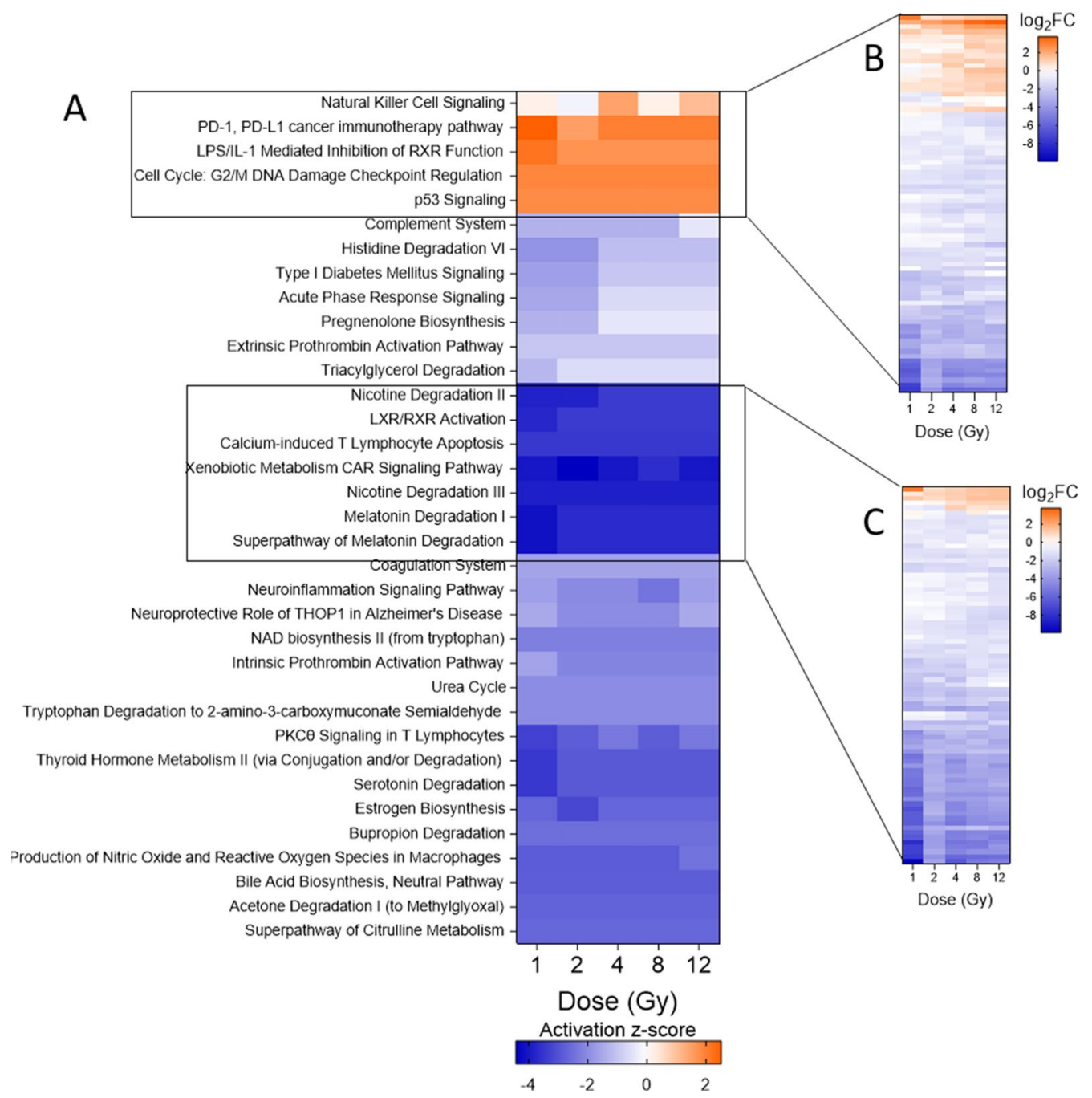

Fig. 5 Predicted canonical pathway dysregulation in mouse heart samples based on all differentially expressed mRNAs. IPA was used to perform pathway analysis on all differentially expressed mRNAs to predict pathway involvement, independent of the target relationship with differentially expressed miRNAs. A Heatmap displays the top 35 most significantly dysregulated pathways (B-H p-value $<0.01$ ). A positive $\mathrm{Z}$-score indicates predicted activation of the pathway based on gene expression and a negative $z$-score indicates predicted deactivation of the pathway based on gene expression. Pathways are hierarchically clustered by z-score. $\mathbf{B}$ Heatmap shows the $\log _{2} \mathrm{FC}$ of the 78 differentially expressed genes with involvement in the cluster of activated pathways. $\mathbf{C}$ Heatmap shows the $\log _{2} \mathrm{FC}$ of 79 differentially expressed genes with involvement in the cluster of most deactivated pathways

activation or deactivation. While natural killer cell signaling was activated significantly after 4 and 12 Gy TBI, the complement system was inhibited across all doses.

Two clusters of pathways showed the most pronounced activation and deactivation. Five pathways were predicted to be activated across all doses, and all were involved in immune response or cell cycle regulation. There were 78 genes differentially expressed in these pathways, a majority of which were downregulated with respect to the control (Fig. 5B). A full list of genes can be found in Additional file 9: Table S7. In contrast to the pathway analysis of the mRNA targets, which showed the highest activation of several pathways after $4 \mathrm{~Gy} \mathrm{TBI}$, all activated pathways except natural killer cell signaling were consistently activated as the dose increased. We observed that radiation inhibits pathways relevant to xenobiotic metabolism and biosynthesis of lipids, including hormones. This is demonstrated by activation of LPS/IL-1 mediated inhibition of RXR function and inhibition of the super-pathway of melatonin degradation, among others. There were 79 genes involved in deactivation of these seven pathways, 
most of which were downregulated after TBI (Fig. 5C, Additional file 9: Table S7).

\section{TBI deactivates metabolic pathways and alters} the expression of metabolism-related genes in heart tissue IPA analysis predicted significant deactivation of several metabolic pathways, such as triacylglycerol degradation and type I diabetes mellitus signaling, among others (Fig. 5A). To further understand how radiation alters metabolism, we used IPA to filter the microarray gene expression data to include only the significantly differentially expressed genes with involvement in metabolic energy production pathways, with emphasis on fatty acid oxidation (Fig. 6A). Of note, there was a significant downregulation of solute carrier $2 \mathrm{a} 2(S l c 2 a 2)$ and concurrent upregulation of pyruvate dehydrogenase kinase $4(P d k 4)$, especially after 4 Gy TBI. Similarly, as dose increased, we observed upregulation of glutamine synthetase (Glul), which encourages conversion of glutamate to glutamine. We also observed downregulation of glutaminase ( $G l s 2)$, which converts glutamine to glutamate.

Gene expression data for fatty acid metabolism at $48 \mathrm{~h}$ post radiation was contradictory. We observed a downregulation of solute carrier $27 \mathrm{a} 5$ (Slc27a5), which is associated with fatty acid entry into the cell; an upregulation of sestrin 2, which inhibits lipid catabolism; and an upregulation of hormone sensitive lipase (Lipe) and adipose triglyceride lipase (Atgl or Pnpla2), which cleave lipid droplets to allow use of fatty acids in FAO. However, there was a downregulation of arylacetamide deacetylase (Aadac) which shares homology with Lipe and is also thought to control triglyceride levels. Additionally, acyl-CoA synthetase medium chain family members 1 (Acsm1) was downregulated, while acyl-CoA thioesterases 1 (Acot1) and acyl-coA dehydrogenase 10 (Acad10) were notably upregulated as radiation doses increased.

\section{Discussion}

Normal tissue damage of the heart is a clinically relevant problem in both therapeutic and accidental exposure to radiation. A previous study highlighted the long term impact of radiation on male macaques, which showed significant myocardial fibrosis and smaller cardiac dimensions at 5.6-9.7 years post radiation exposure with 6.5-8.4 Gy [65]. Historical data for macaques receiving TBI, the $\mathrm{LD}_{50 / 30}$ post $\mathrm{X}$-ray irradiation varies between 4.92 and 7.18 Gy [66]. In contrast, $\mathrm{LD}_{50 / 30}$ is approximately 7.2 Gy in female mice receiving TBI X-ray

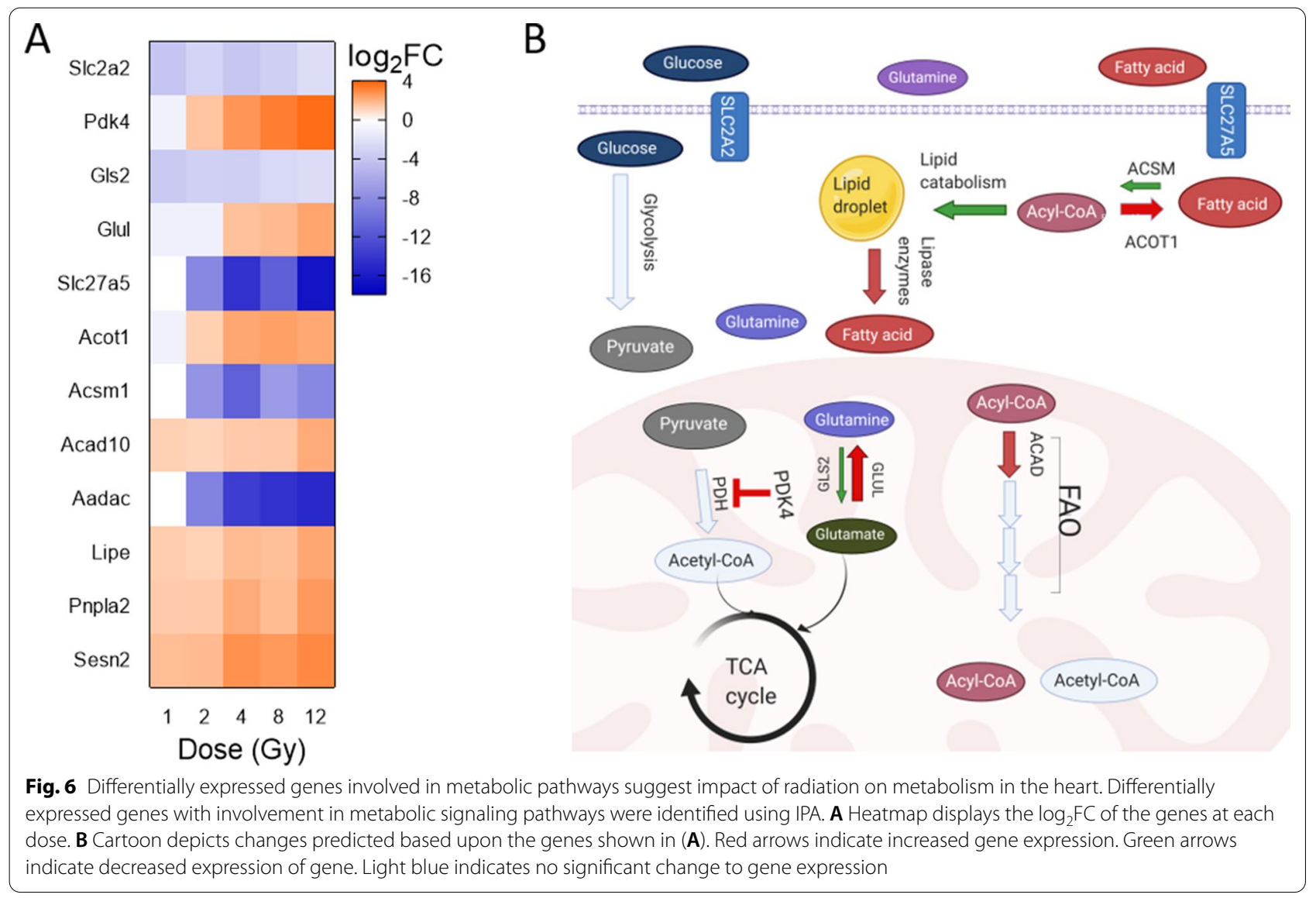


[67]. Our study focused on short term (48 h) changes in gene expression after TBI doses in mice. Understanding mechanisms and markers of radiation injury at an early time-point following exposure can improve methods to mitigate long-term damage and death. Recent research in the radiation biodosimetry field indicates the importance of looking for alterations in multiple biomarkers rather than relying on a single marker $[68,69]$. To this end, we have identified changes in multiple mRNAs, miRNAs, and lncRNAs across doses to provide potential markers of tissue damage.

\section{TBI dysregulates pathways relevant to cell cycle arrest,} hemoglobin synthesis and immune response in the heart

The observed early changes in gene expression led to significant dysregulation of pathways commonly associated with radiation exposure, including cell cycle arrest, apoptosis, and senescence. The most significantly altered genes, Cdkn1a and Ckap2, are capable of inducing cell cycle arrest or apoptosis under stress conditions [70, 71]. The observed upregulation of Gdf15 and downregulation of Aplnr are associated with stress induced senescence and have previously been reported as biomarkers of radiation exposure [56, 72, 73]. The inversely correlated expression of miRNAs and their mRNA targets that are associated with these pathways provides insight into the potential mechanisms of acute effects of TBI and targets to mitigate acute and delayed effects on heart tissue. Prior research demonstrated miR-128 negatively regulated Wee1 and Tgfbrl, genes involved in mitotic inhibition [74-76]. Additionally, miR-122 is known to increase radiation sensitivity and targets Slca11 and $F A M 117 b$ [77]. While little is known about the function of Fam117b, Slc7a11 downregulation is associated with RT-induced ferroptosis in tumor cells $[78,79]$. The miR-17-92 cluster represses E2F1-3 to regulate cell proliferation and apoptosis, and includes miR-18a [80]. A negative feedback loop has been observed within this cluster, as E2F1 upregulates miR-17-92 which causes increased repression of the genes E2F1-3 [81]. Mechanistic studies are required to confirm the miRNA-mRNA interdependent functions in our data. Similarly, further research into lncRNA-mRNA functions are also needed. Acute lncRNA Dino overexpression caused an increase in Cdkn1a expression in cervical cancer cells [82]. Our data suggests an interplay between both lncRNA Dino and mRNA Cdkn1a expression.

Anemia and decreased hemoglobin levels are a known side effect of RT [83]. We observed decreased expression levels of genes relevant to hemoglobin synthesis. Alas2, the rate limiting enzyme in heme synthesis, became increasingly downregulated as radiation dose increased. Similar downregulation of Alas2 was recently cited as a potential predictive marker for radiation induced hematological toxicity in cancer patients [60]. Other genes associated with hemoglobin synthesis, including $\mathrm{Hbb}$ $b t, H b b-b 1$, and $H b a-a 1$, were also significantly, linearly downregulated (Additional file 3: Table S2).

Our pathway analysis also indicated inflammatory pathways are downregulated at higher dose levels at $48 \mathrm{~h}$ post-radiation. Of note, TBI induced significant downregulation of $C \times 3 \mathrm{crl}$, which is known to induce recruitment of immune cells and an inflammatory response in smooth muscle and endothelial cells [84]. Short-term data contrasts long-term in vivo data that showed upregulation of inflammatory markers in the heart of a mouse model 40 days post-irradiation [17]. Additional studies that include intermediate timepoints are needed to clarify when the heart transitions from an anti-inflammatory to a pro-inflammatory response after radiation to enable improved treatment options.

Consistent with previous research [85], our findings indicated inhibition of extrinsic and intrinsic prothrombic pathways that couple with inhibition of coagulation pathway after radiation exposure. Radiation is known to increase likelihood of coagulopathy, which can lead to death when untreated [86]. We also observed downregulation of hemoglobin subunit beta $(H b b)$ and hemoglobin subunit alpha ( $\mathrm{Hba}$ ) (Additional file 3: Table S2). In combination with anemia, failure to clot produces hemostatic dysfunction and potential death, though the pathogenesis is poorly understood [87]. Our research highlights these alterations in gene expression to provide insight into potential mechanisms of and therapeutic targets for acute radiation syndrome (ARS).

Retinoid X receptor and liver X receptor (RXR/LXR) activation is associated with protection against heart failure due to their role in improving glucose tolerance, decreasing lipid accumulation, and decreasing inflammation [88]. RXR signaling has previously been shown to increase estradiol synthesis from pregnenolone [89]. We observed that the estrogen and pregnenolone biosynthesis pathways are also inhibited. Inhibition of RXR/LXR and its downstream pathways coupled with inhibition of triacylglycerol degradation may indicate a deleterious increase in lipid accumulation within the heart.

\section{Radiation induced IncRNA and miRNA provide potential insight into RIHD through signaling pathways}

Previously, we reported the concomitant differential expression of p53-related lncRNAs such as Pvt1, Dino, Trp3cor 1 after TBI in a mouse model [44]. In the current study, we observed significant alterations in abhydrolase domain containing 11, opposite strand (Abhd11os), Pvt1, Trp3cor1, Kalrn, linc-RNA activator of myogenesis (Linc-RAM), lncRNA 
chr10:69819062-69871640_F and Dino. Increased expression of Abhd11os has previously been shown to decrease lesion size in a Huntington's disease mouse model and the authors reported its crucial roles in neurodegenerative diseases [90], but the exact mechanism is still unclear. Linc-RAM encourages adult skeletal muscle stem cells to differentiate into skeletal muscle through myogenic differentiation (MyoD), which aids in muscle repair after injury [91, 92]. While Linc-RAM has not been directly associated with cardiomyocytes, MyoD-null dystrophin-null transgenic mice develop severe cardiomyopathy [93]. Pvt1 has been associated with radiation resistance in cancer cells and cardiac hypertrophy in cardiomyocytes [94-96]. Previous studies showed that $P v t 1$ binds $C d k n 1 a$ and miR-149-3p to suppress their activity in primary chondrocytes and Burkitt lymphoma Rajit cells, respectively [97, 98]. In contrast, $G d f 15$ is a downstream target of $P v t 1$ and was positively regulated by the lncRNA in hepatocellular carcinoma cells [99]. Our data indicates an increase in expression of Pvt1, miR-149-3p, Cdkn1a and Gdf15 by $12 \mathrm{~Gy}$, suggesting that the interactions between these noncoding and coding RNA must be further elucidated in normal tissue. Further, the clinical relevance of lncRNA chr10:69819062-69871640_F has yet to reported. With the observed significant expression changes across all doses of radiation, further studies are crucial to inform more conclusions about the role of this lncRNA in the heart's response to radiation.

Prior research demonstrated the integral role that miRNAs play in cardiac fibrosis and proliferation as well as response to radiation injury [100, 101]. We therefore anticipated changes in miRNA expression in heart tissue after TBI. Surprisingly, and possibly due to the early time point and stringent statistical analysis, we only observed significant upregulation of miRNAs at 1 Gy and 12 Gy. Among the up-regulated miRNAs, miR-149-3p has previously been implicated in multiple functions, including cell migration repression and metabolic modifications in A549 cells, a non-small cell lung carcinoma (NSCLC) model [102]. Additionally, miR-211 has been demonstrated to decrease cell proliferation and metastasis in vitro in breast and renal cell carcinoma models [103, 104], while miR-3960 has been implicated in calcification, decreased elasticity, and cardiac dysfunction in vascular smooth muscle cells of male C57BL/6 mouse aortas [105]. Arterial calcification and valvular, ventricular, and diastolic dysfunction are well-known complications of RIHD disease [106]. While the functions of certain miRNAs are not well understood, previous studies indicate that miR-8101 and miR-6538 are associated with heart failure [107, 108].
TBI causes miRNA and mRNA expression changes that may indicate similar pathogenesis of end-stage heart failure Upregulation of miR-149-3p is associated with inhibition of glucose metabolism. Its role as a therapeutic target to protect against diet-induced obesity and metabolic dysfunctions was shown previously in both colorectal cancer patients, tumors taken from colorectal cancer patients and male C57BL/6 J [109, 110]. In general, the observed changes in metabolism-related gene expression suggest that fatty acids are not being used for catabolism (Fig. 6B). Increasing doses of radiation appear to inhibit glucose oxidation through increased expression of $P d k 4$, which uncouples glycolysis from oxidative phosphorylation by blocking pyruvate dehydrogenase $(P d h)$, and decreased expression of Acsm1 [111, 112]. However, we also observed a significant downregulation of the transporter Slc27a5, which would inhibit entry of fatty acids into the cell for anabolic or catabolic use. This could be a fatal side effect of IR exposure because the adult heart relies on fatty acid oxidation as its main source of energy production [113]. Since Lipe and Pnpla2 were upregulated, the heart may be relying on internal stores of triacylglycerol to produce energy. Aside from Acsm1, no overall changes in acyl-CoA synthetases were observed; these enzymes combine fatty acids with Coenzyme A for use in FAO or lipogenesis. We observed upregulation of Acot1 which plays contradictory roles in FAO as it can separate long chain fatty acids from coenzyme A to decrease the available substrate pool [114]. However, prior research indicates $A \cot 1$ also increases FAO through activation of peroxisome proliferator-activated receptor $\alpha(P p a r-\alpha)$, which upregulates Acad variants [115-117]. We only observed an upregulation of Acad10 and there was no significant change to Ppar- $\alpha$ or other Acad variants at $48 \mathrm{~h}$ after radiation. Furthermore, there was no change in expression of other genes within the FAO pathway. This inhibition of glucose oxidation paired with an apparent reliance on FAO and an increase in free fatty acids matches what is seen in some forms of end stage heart failure $[118,119]$.

\section{Gene expression changes in TBI C57BI/6 match those identified in previous study of TBI Gottingen minipigs} A recent study from our lab reported survival predictive signatures inherent to heart, lung and liver in TBI Gottingen minipigs [120]. Increased expression of $P d k 4$ was significantly upregulated in the hearts of non-surviving (survived $<7$ days post-TBI) minipigs. We also observed increased expression of $P d k 4$ at 4-12 Gy radiation. As previously mentioned, the upregulation of $P d k 4$ is associated with decreased glucose oxidation and potential failure of energy production. Hearts from these non-surviving minipigs showed a decrease in the Apelin signaling 
pathway when compared to survivors and sham animals. In the present study, we also observed inhibition of the Apelin signaling pathway starting at 2 Gy. Apelin signaling is important for endothelial cell proliferation and migration and has been shown to inhibit TGF- $\beta$ induced cardiac fibrosis and senescence [121]. Conversely, downregulation of Apelin has been linked to heart failure and ventricular dysfunction [122]. Both these findings implicate centrality of the endothelial cell damage in radiation induced heart injury. Finding consistency between mouse and minipig studies indicates conservation of the radiation response across species, suggesting that rescuing the function of this pathway may prevent RIHD in humans as well.

Similarities in TBI-induced gene expression between heart and blood samples indicates potential biomarkers for effective triaging with radiation biodosimetry

Finding normal tissue injury markers in a less invasive way is warranted for clinical applications. From this perspective, we looked at the commonality of gene and lncRNA expression changes between heart tissue of the current study and mouse whole blood after TBI from a study previously published by our group [44]. Interestingly, we detected few genes in common between both mouse heart tissue and whole blood. We focused on genes altered at $48 \mathrm{~h}$ after $8 \mathrm{~Gy}$ in whole blood and compared these alterations to changes found in our current study of mouse heart tissue. Significantly altered genes included Cdkn1a, Pmaip1, H2Aa, H2Ba1, Cx3cr1, Snca, and Gm9992 (Additional file 10: Table S8). Another previous study from our lab indicated that $P v t 1$ was significantly expressed in whole blood as early as $16 \mathrm{~h}$ after at least 2 Gy TBI, and was sustained until $48 \mathrm{~h}$ after TBI [44]. Similarly, at 48 h post-TBI, Trp53cor 1 and Dino were significantly upregulated in the whole blood of 12 Gy and 8 Gy TBI mice, respectively. We observed similar expression patterns of these lncRNAs in heart samples after $48 \mathrm{~h}$.

We also compared the heart data to a previously reported in vitro study of gene expression changes in human coronary artery endothelial cells (HCAEC) at $24 \mathrm{~h}$ after $10 \mathrm{~Gy}$ of single dose radiation [42]. The genes Cdkn1a, growth differentiation factor 15 (Gdf15), and DNA damage-inducible transcript 4 (Ddit4/Redd1) have previously been reported as radiation markers [72, 123, 124]. They showed concomitant upregulation in mouse heart tissue (Additional file 10: Table S8) and in HCAEC [42]. Additionally, we noted the upregulation of hypoxia-inducible factor $3 \mathrm{a}$ ( $\mathrm{Hif3a}$ ) and insulin-like growth factor 1 (Igf1) in mouse heart tissue, whereas these two genes showed significant downregulation in HCAEC in vitro study. In rat cardiomyocytes, Hif3a silencing led to increased cell viability and decreased necrosis after hypoxia challenge, suggesting decreased Hif3a expression is cardioprotective [125]. In a population study of elderly individuals, decreased serum Igf1 expression was shown to be a risk factor for mortality after ischemic heart disease [126]. These regulation inconsistencies may stem from differences between models, time points, and radiation dose rate between in vivo and in vitro experiments.

\section{Future directions}

With the use of thoracic RT and the continued risk of a large-scale nuclear exposure incident inadvertently causing potential damage to the heart, understanding the effects of IR exposure on critical organs such as the heart will improve patient outcomes. For clinical management, early biomarkers could be predictive of later damage, enabling alteration of the dose to the organs at risk, use of medical countermeasures, or implementation of an appropriate long-term medical management strategy. For a nuclear exposure incident, the dose will have been delivered such that the injury falls within delayed effects of acute radiation exposure (DEARE), but the mitigator and medical-management approach would still be relevant.

In addition to identifying blood-based signatures for rapid triaging, we are also working on identifying expression changes within organs (e.g., heart, lungs, liver) affected by radiation to predict both short- and long-term organ injury. It is therefore clinically relevant to determine the response of the markers to fractionated radiation and in the presence of pre-existing conditions. Palayoor et al. showed more pronounced miRNA and mRNA expression changes in an in vitro HCAEC model after multifractionated radiation compared to a single dose of radiation suggesting that we may see similar trends in vivo [42]. Additionally, a study of acute lymphocytic leukemia patients that received six fractions of 2 Gy TBI showed a significant and sustained increase in blood-based Cdkn1a after each fraction [127]. Blood from these pediatric cancer patients also showed higher baseline levels of $C d k n 1 a$ expression compared to healthy controls, demonstrating the importance of addressing the effects of confounding factors on expression changes. Recognizing that heart biopsies would not be a suitable method to triage patients in an exposure scenario, we are also currently investigating the short- and long-term circulating RNA response of non-human primates exposed to whole thorax irradiation. This would not only enable monitoring of organ-specific damage sustained during accidental exposures but would also have applications in predicting normal tissue toxicity as a side-effect of RT for the treatment of cancer. 


\section{Abbreviations}

RT: Radiotherapy; IR: Ionizing radiation; miRNAs: MicroRNAs; IncRNAs: Long non-coding RNAs; mRNAs: Messenger RNAs.

\section{Supplementary Information}

The online version contains supplementary material available at https://doi. org/10.1186/s12967-021-02998-w.

\section{Additional file 1: Figure S1. RT-qPCR validation of mRNA biomarker} expression in heart tissue. The microarray results were confirmed by RT-qPCR for Aplnr, Gdf15, Cdkn1a, Ckap2, Cx3cr1, and Alas2. Fold change values relative to $0 \mathrm{~Gy}$ are shown for the three samples each at 1, 2, 4, 8, and $12 \mathrm{~Gy}$. An asterisk $\left(^{*}\right)$ indicates statistically significant value by student t-test, comparing control to irradiated sample ( $p$-value $<0.05$ ).

Additional file 2: Table S1. Differentially expressed genes at each dose compared to controls. Each tab corresponds to a specific dose. Columns B through $\mathrm{G}$ list the Agilent probe ID, systematic name (ID of target sequence designed to hybridize with the Agilent probe), $\mathrm{p}$-value, Benjamini-Hochberg adjusted p-value, B statistic (log of the odds that the gene is differentially expressed), and the average $\log _{2} F C$ across samples exposed to the dose, respectively. Probes are listed in order of decreasing significance.

Additional file 3: Table S2. Top 20 most significantly up- and downregulated $m R N A s$ that showed a linear trend across all doses. Tables of up-regulated (A) and down-regulated (B) linear, or dose-responsive, mRNAs. Gene symbol, systematic name, Benjamini-Hochberg adjusted p-value, B statistic, and the average $\log _{2} F C$ across all doses are shown in each table. Genes are listed in order of decreasing significance.

Additional file 4: Table S3. Differentially expressed IncRNAs at each dose compared to controls. Each tab corresponds to a specific dose. Columns B through $\mathrm{G}$ list the Agilent probe ID, systematic name, $\mathrm{p}$-value, Benjamini-Hochberg adjusted $\mathrm{p}$-value, $\mathrm{B}$ statistic, and the average $\log _{2} \mathrm{FC}$ across samples exposed to the dose, respectively. Probes are listed in order of decreasing significance.

Additional file 5: Table S4. Significantly up- and down-regulated IncRNAs that showed a linear trend across all doses. Table of up- and down-regulated linear, or dose-responsive, IncRNAs. IncRNA symbol (if annotated), systematic name, Benjamini-Hochberg adjusted $\mathrm{p}$-value, $\mathrm{B}$ statistic, and the average $\log _{2}$ FC across all doses are shown in each table. For unannotated IncRNAs, a BLAT analysis was performed using ensmbl. org and the overlapping transcript, if any, was listed in the table. The asterisk $\left(^{*}\right)$ denotes the transcripts identified through BLAT. IncRNAs are listed in order of decreasing significance.

Additional file 6: Table S5. Differentially expressed miRNAs at each dose compared to controls. Each tab corresponds to miRNAs that were significantly differentially expressed at the specific dose. Columns B through $\mathrm{G}$ list the Agilent probe ID, systematic name, p-value, BenjaminiHochberg adjusted $\mathrm{p}$-value, $\mathrm{B}$ statistic, and the average $\log _{2} \mathrm{FC}$ across samples exposed to the dose, respectively. Probes are listed in order of decreasing significance.

\section{Additional file 7: Table S6. Top 20 most significant miRNAs that} showed a linear trend across all doses. Table of up-regulated linear, or dose-responsive, miRNAs. IncRNA symbol (if annotated), systematic name, Benjamini-Hochberg adjusted p-value, B statistic, and the average $\log _{2} \mathrm{FC}$ across all doses are shown in each table. For unannotated IncRNAs, a BLAT analysis was performed using ensmbl.org and the overlapping transcript, if any, was listed in the table. The asterisk ${ }^{*}$ ) denotes the transcripts identified through BLAT. IncRNAs are listed in order of decreasing significance.

Additional file 8: Figure S2. RT-qPCR validation of miRNA biomarker expression in heart tissue. The microarray results were confirmed by RT-qPCR for miR-149-3p, miR-103a-3p, miR-6538, miR-3960, miR-7118, and $\mathrm{miR}-8101$. Fold change values relative to $0 \mathrm{~Gy}$ are shown for the three samples each at 1, 2, 4, 8, and 12 Gy. An asterisk (*) indicates statistically significant value by student t-test, comparing control to irradiated sample (p-value $<0.05)$.
Additional file 9: Table S7. Differentially expressed genes with involvement in the most activated and most deactivated pathways. A list of differentially expressed genes and the corresponding $\log _{2} \mathrm{FC}$ at each dose are included in each tab. The 78 genes in the activated pathways are listed in the first tab, and the 79 genes in the deactivated pathways are listed in the second tab.

Additional file 10: Table S8. Top 20 probes differentially expressed in a dose dependent manner in the heart samples compared to differentially expressed genes from whole blood collected from the same animals at $48 \mathrm{~h}$ timepoint and also compared to Human Coronary Artery Endothelial cells exposed to $10 \mathrm{~Gy}$ radiation at $24 \mathrm{~h}$ timepoints.

\section{Acknowledgements}

This study was supported by the NIH Intramural Research Program, National Cancer Institute, Center for Cancer Research and National Institute of Allergy and Infectious Diseases (IAA No. NRC-13028). We thank Dr. Eric Bernhard for his expert advice in editing the manuscript. The authors would also like to thank Juan Dalo and Kevin Scott for technical expertise and assistance.

\section{Authors' contributions}

Conceptualization was by MJA and CNC. Funding acquisition and supervision were by MJA and CNC. Methodology was by MJA, SM, JMM, SC, and MB. Animal experiments were conducted by CVB. Investigation was by MJA, JMM, $M B$, and SM. Statistical analysis was performed by LM, LS, and JS. Original draft writing was by MJA, MB, SM, and JMM. Manuscript editing and revisions were by MJA, MB, JMM, SM, IE, AS, and CNC. All authors read and approved the final manuscript.

\section{Funding}

This work was supported by NIAID (IAA \#NRC-13028).

Availability of data and materials

Research data and material are stored in an institutional repository and will be shared upon request to the corresponding author.

\section{Declarations}

Ethics approval and consent to participate

Not applicable.

\section{Consent for publication}

All the authors have read and approved the manuscript in all respects for publication.

\section{Competing interests}

There are no competing interests declared by the authors.

\section{Author details}

${ }^{1}$ Radiation Oncology Branch, Center for Cancer Research, National Cancer Institute, National Institutes of Health, 10 Center Drive, Room B3B406, Bethesda, MD 20892, USA. ${ }^{2}$ Gryphon Scientific, Takoma Park, MD 20912, USA. ${ }^{3}$ Department of Radiation Oncology, Weill Cornell Medicine, New York, NY 10065, USA. ${ }^{4}$ Department of Radiation Oncology, Stanford University School of Medicine, Stanford, CA 94305, USA. ${ }^{5}$ Radiation Research Program, National Cancer Institute, National Institutes of Health, Rockville, MD 20850, USA.

Received: 3 December 2020 Accepted: 23 July 2021

Published online: 07 August 2021

\section{References}

1. Dracham CB, Shankar A, Madan R. Radiation induced secondary malignancies: a review article. Radiat Oncol J. 2018;36:85-94. https://doi.org/ 10.3857/roj.2018.00290.

2. Darby S, McGale P, Peto R, Granath F, Hall P, Ekbom A. Mortality from cardiovascular disease more than 10 years after radiotherapy for breast 
cancer: nationwide cohort study of 90000 Swedish women. Br Med J. 2003;326:256-7. https://doi.org/10.1136/bmj.326.7383.256.

3. Desai MY, Jellis CL, Kotecha R, Johnston DR, Griffin BP. Radiation-associated cardiac disease: a practical approach to diagnosis and management. JACC Cardiovasc Imaging. 2018;11:1132-49. https://doi.org/10. 1016/j.jcmg.2018.04.028.

4. Denham JW, Hauer-Jensen M. The radiotherapeutic injury—a complex "wound." Radiother Oncol. 2002;63:129-45. https://doi.org/10.1016/ S0167-8140(02)00060-9.

5. Shimizu Y, Kodama K, Nishi N, Kasagi F, Suyama A, Soda M, et al. Radiation exposure and circulatory disease risk: Hiroshima and Nagasaki atomic bomb survivor data, 1950-2003. BMJ. 2010;340:193. https://doi. org/10.1136/bmj.b5349.

6. Shimizu Y, Pierce DA, Preston DL, Mabuchi K. Studies of the mortality of atomic bomb survivors. Report 12, part II. Noncancer mortality: 1950-1990. Radiat Res. 1999;152:374-89. https://doi.org/10.2307/35802 22.

7. Preston DL, Shimizu Y, Pierce DA, Suyama A, Mabuchi K. Studies of mortality of atomic bomb survivors. Report 13: solid cancer and noncancer disease mortality: 1950-1997. Radiat Res. 2003;160:381-407. https://doi. org/10.1667/RR3049.

8. Kashcheev VV, Chekin SY, Karpenko SV, Maksioutov MA, Menyaylo AN, Tumanov KA, et al. Radiation risk of cardiovascular diseases in the cohort of russian emergency workers of the chernobyl accident. Health Phys. 2017;113:23-9. https://doi.org/10.1097/HP.0000000000000670.

9. Sardaro A, Petruzzelli MF, D'Errico MP, Grimaldi L, Pili G, Portaluri M. Radiation-induced cardiac damage in early left breast cancer patients: risk factors, biological mechanisms, radiobiology, and dosimetric constraints. Radiother Oncol. 2012;103:133-42. https://doi.org/10.1016/j. radonc.2012.02.008.

10. Heidenreich PA, Schnittger I, Strauss HW, Vagelos RH, Lee BK, Mariscal $\mathrm{CS}$, et al. Screening for coronary artery disease after mediastinal irradiation for Hodgkin's disease. J Clin Oncol. 2007;25:43-9. https://doi.org/ 10.1200/JCO.2006.07.0805.

11. Cella L, Oh JH, Deasy JO, Palma G, Liuzzi R, D'Avino V, et al. Predicting radiation-induced valvular heart damage. Acta Oncol (Madr). 2015;54:1796-804. https://doi.org/10.3109/0284186X.2015.1016624

12. Cuzick J, Stewart H, Rutqvist L, Houghton J, Edwards R, Redmond C, et al. Cause-specific mortality in long-term survivors of breast cancer who participated in trials of radiotherapy. J Clin Oncol. 1994;12:447-53. https://doi.org/10.1200/JCO.1994.12.3.447.

13. Ping Z, Peng $Y$, Lang $H$, Xinyong $C$, Zhiyi Z, Xiaocheng $W$, et al. Oxidative stress in radiation-induced cardiotoxicity. Oxid Med Cell Longev. 2020. https://doi.org/10.1155/2020/3579143.

14. De Moor JS, Mariotto AB, Parry C, Alfano CM, Padgett L, Kent EE, et al. Cancer survivors in the united states: prevalence across the survivorship trajectory and implications for care. Cancer Epidemiol Biomarkers Prev. 2013:22:561-70. https://doi.org/10.1158/1055-9965.EPI-12-1356.

15. Curigliano G, Cardinale D, Dent S, Criscitiello C, Aseyev O, Lenihan D, et al. Cardiotoxicity of anticancer treatments: epidemiology, detection, and management. CA Cancer J Clin. 2016;66:309-25. https://doi.org/10. 3322/caac.21341.

16. Gujral DM, Lloyd G, Bhattacharyya S. Radiation-induced valvular heart disease. Heart. 2016;102:269-76. https://doi.org/10.1136/heart jnl-2015-308765.

17. Stewart FA, Seemann I, Hoving S, Russell NS. Understanding radiationinduced cardiovascular damage and strategies for intervention. Clin Oncol. 2013;25:617-24. https://doi.org/10.1016/j.clon.2013.06.012.

18. Maraldo MV, Giusti F, Vogelius IR, Lundemann M, van der Kaaij MAE, Ramadan S, et al. Cardiovascular disease after treatment for Hodgkin's Iymphoma: an analysis of nine collaborative EORTC-LYSA trials. Lancet Haematol. 2015;2:e492-502. https://doi.org/10.1016/S2352-3026(15) 00153-2.

19. Kuo AH, Ancukiewicz M, Kozak KR, Yock TI, Padera TP. Cardiac and inflammatory biomarkers do not correlate with volume of heart or lung receiving radiation. Radiat Oncol. 2015. https://doi.org/10.1186/ s13014-014-0324-1.

20. Dicarlo AL, Tamarat R, Rios Cl, Benderitter M, Czarniecki CW, Allio TC, et al. Cellular therapies for treatment of radiation injury: report from a NIH/NIAID and IRSN workshop. Radiat Res. 2017;188:e54-75. https://doi. org/10.1667/RR14810.1.
21. Slezak J, Kura B, Babal P, Barancik M, Ferko M, Frimmel K, et al. Potential markers and metabolic processes involved in the mechanism of radiation-induced heart injury. Can J Physiol Pharmacol. 2017;95:1190-203. https://doi.org/10.1139/cjpp-2017-0121.

22. Azimzadeh O, Azizova T, Merl-Pham J, Subramanian V, Bakshi MV, Moseeva $\mathrm{M}$, et al. A dose-dependent perturbation in cardiac energy metabolism is linked to radiation-induced ischemic heart disease in Mayak nuclear workers. Oncotarget. 2017;8:9067-78. https://doi.org/10. 18632/oncotarget.10424.

23. Zhang Y, Luo G, Zhang Y, Zhang M, Zhou J, Gao W, et al. Critical effects of long non-coding RNA on fibrosis diseases. Exp Mol Med. 2018;50:428. https://doi.org/10.1038/emm.2017.223.

24. Vliegenthart ADB, Shaffer JM, Clarke JI, Peeters LEJ, Caporali A, Bateman DN, et al. Comprehensive microRNA profiling in acetaminophen toxicity identifies novel circulating biomarkers for human liver and kidney injury. Sci Rep. 2015. https://doi.org/10.1038/srep15501.

25. Matkovich SJ, Edwards JR, Grossenheider TC, De Guzman SC, Dorn GW. Epigenetic coordination of embryonic heart transcription by dynamically regulated long noncoding RNAs. Proc Natl Acad Sci USA. 2014;111:12264-9. https://doi.org/10.1073/pnas.1410622111.

26. Ounzain S, Micheletti R, Beckmann T, Schroen B, Alexanian M, Pezzuto I, et al. Genome-wide profiling of the cardiac transcriptome after myocardial infarction identifies novel heart-specific long non-coding RNAs. Eur Heart J. 2015;36:353-68. https://doi.org/10.1093/eurhearti/ehu180.

27. Yang KC, Yamada KA, Patel AY, Topkara VK, George I, Cheema FH, et al. Deep RNA sequencing reveals dynamic regulation of myocardial noncoding RNAs in failing human heart and remodeling with mechanical circulatory support. Circulation. 2014;129:1009-21. https://doi.org/10. 1161/CIRCULATIONAHA.113.003863.

28. Sallam T, Sandhu J, Tontonoz P. Long noncoding RNA discovery in cardiovascular disease: decoding form to function. Circ Res. 2018;122:15566. https://doi.org/10.1161/CIRCRESAHA.117.311802.

29. Zangrando J, Zhang L, Vausort M, Maskali F, Marie PY, Wagner DR, et al. Identification of candidate long non-coding RNAs in response to myocardial infarction. BMC Genomics. 2014. https://doi.org/10.1186/ 1471-2164-15-460.

30. Lin F, Gong X, Yu P, Yue A, Meng Q, Zheng L, et al. Distinct circulating expression profiles of long noncoding RNAs in heart failure patients with ischemic and nonischemic dilated cardiomyopathy. Front Genet. 2019. https://doi.org/10.3389/fgene.2019.01116.

31. Poller W, Dimmeler S, Heymans S, Zeller T, Haas J, Karakas M, et al. Noncoding RNAs in cardiovascular diseases: diagnostic and therapeutic perspectives. Eur Heart J. 2018;39:2704-16. https://doi.org/10.1093/ eurheartj/ehx165.

32. Papait R, Kunderfranco P, Stirparo GG, Latronico MVG, Condorelli G. Long noncoding RNA: a new player of heart failure? J Cardiovasc Transl Res. 2013;6:876-83. https://doi.org/10.1007/s12265-013-9488-6.

33. Metheetrairut C, Slack FJ. MicroRNAs in the ionizing radiation response and in radiotherapy. Curr Opin Genet Dev. 2013;23:12-9. https://doi. org/10.1016/j.gde.2013.01.002.

34. Wojciechowska A, Braniewska A, Kozar-Kamińska K. MicroRNA in cardiovascular biology and disease. Adv Clin Exp Med. 2017;26:865-74. https://doi.org/10.17219/acem/62915.

35. Wang K, Long B, Li N, Li L, Liu CY, Dong YH, et al. MicroRNA-2861 regulates programmed necrosis in cardiomyocyte by impairing adenine nucleotide translocase 1 expression. Free Radic Biol Med. 2016;91:5867. https://doi.org/10.1016/j.freeradbiomed.2015.11.031.

36. Jakob P, Landmesser U. Role of microRNAs in stem/progenitor cells and cardiovascular repair. Cardiovasc Res. 2012;93:614-22. https://doi.org/ 10.1093/cvr/cvr311.

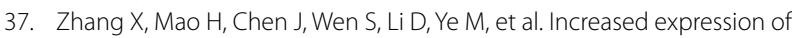
microRNA-221 inhibits PAK1 in endothelial progenitor cells and impairs its function via c-Raf/MEK/ERK pathway. Biochem Biophys Res Commun. 2013:431:404-8. https://doi.org/10.1016/j.bbrc.2012.12.157.

38. Terradas M, Martín M, Repullès J, Huarte M, Genescà A. Distinct sets of IncRNAs are differentially modulated after exposure to high and low doses of X rays. Radiat Res. 2016;186:549-58. https://doi.org/10.1667/ RR14377.1.

39. Nie J, Peng C, Pei W, Zhu W, Zhang S, Cao H, et al. A novel role of long non-coding RNAs in response to X-ray irradiation. Toxicol Vitr. 2015;30:536-44. https://doi.org/10.1016/j.tiv.2015.09.007. 
40. Beer L, Nemec L, Wagner T, Ristl R, Altenburger LM, Ankersmit HJ, et al. lonizing radiation regulates long non-coding RNAs in human peripheral blood mononuclear cells. J Radiat Res. 2017;58:201-9. https://doi. org/10.1093/jrr/rrw111.

41. Liang X, Zheng S, Cui J, Yu D, Yang G, Zhou L, et al. Alterations of MicroRNA expression in the liver, heart, and testis of mice upon exposure to repeated low-dose radiation. Dose Response. 2018. https://doi.org/10. $1177 / 1559325818799561$.

42. Palayoor ST, John-Aryankalayil M, Makinde AY, Falduto MT, Magnuson SR, Coleman CN. Differential expression of stress and immune response pathway transcripts and miRNAs in normal human endothelial cells subjected to fractionated or single-dose radiation. Mol Cancer Res. 2014;12:1002-15. https://doi.org/10.1158/1541-7786.MCR-13-0623.

43. Rogers CJ, Lukaszewicz Al, Yamada-Hanff J, Micewicz ED, Ratikan JA, Starbird MA, et al. Identification of miRNA signatures associated with radiation-induced late lung injury in mice. PLoS ONE. 2020. https://doi. org/10.1371/journal.pone.0232411.

44. Aryankalayil MJ, Chopra S, Levin J, Eke I, Makinde A, Das S, et al. Radiation-induced long noncoding RNAs in a mouse model after whole-body irradiation. Radiat Res. 2018;189:251-63. https://doi.org/10. 1667/RR14891.1.

45. Bhattacharya S, Asaithamby A. lonizing radiation and heart risks. Semin Cell Dev Biol. 2016;58:14-25. https://doi.org/10.1016/j.semcdb.2016.01. 045.

46. Aryankalayil MJ, Chopra S, Makinde A, Eke I, Levin J, Shankavaram U, et al. Microarray analysis of miRNA expression profiles following whole body irradiation in a mouse model. Biomarkers. 2018;23:689-703. https://doi.org/10.1080/1354750X.2018.1479771.

47. Schmitt AM, Garcia JT, Hung T, Flynn RA, Shen Y, Qu K, et al. An inducible long noncoding RNA amplifies DNA damage signaling. Nat Genet. 2016:48:1370-6. https://doi.org/10.1038/ng.3673.

48. Ritchie ME, Phipson B, Wu D, Hu Y, Law CW, Shi W, et al. Limma powers differential expression analyses for RNA-sequencing and microarray studies. Nucleic Acids Res. 2015;43: e47. https://doi.org/10.1093/nar/ gkv007.

49. Ritchie ME, Silver J, Oshlack A, Holmes M, Diyagama D, Holloway A, et al. A comparison of background correction methods for two-colour microarrays. Bioinformatics. 2007;23:2700-7. https://doi.org/10.1093/ bioinformatics/btm412.

50. Smyth GK. Linear models and empirical bayes methods for assessing differential expression in microarray experiments. Stat Appl Genet Mol Biol. 2004. https://doi.org/10.2202/1544-6115.1027.

51. Aken BL, Ayling S, Barrell D, Clarke L, Curwen V, Fairley S, et al. The Ensembl gene annotation system. Database. 2016. https://doi.org/10. 1093/database/baw093.

52. Agarwal V, Bell GW, Nam JW, Bartel DP. Predicting effective microRNA target sites in mammalian mRNAs. Elife. 2015. https://doi.org/10.7554/ elife.05005.

53. Lee WJ, Majumder ZR, Jeoung D, Lee HJ, Kim SH, Bae S, et al. Organspecific gene expressions in C57BL/6 mice after exposure to low-dose radiation. Radiat Res. 2006;165:562-9. https://doi.org/10.1667/RR3549.1.

54. Zeng ZM, Du HY, Xiong L, Zeng XL, Zhang P, Cai J, et al. BRCA1 protects cardiac microvascular endothelial cells against irradiation by regulating p21-mediated cell cycle arrest. Life Sci. 2020. https://doi.org/10.1016/j. Ifs.2020.117342.

55. Wang T, Liu J, McDonald C, Lupino K, Zhai X, Wilkins BJ, et al. GDF 15 is a heart-derived hormone that regulates body growth. EMBO Mol Med. 2017;9:1150-64. https://doi.org/10.15252/emmm.201707604.

56. Park H, Kim CH, Jeong JH, Park M, Kim KS. GDF15 contributes to radiation-induced senescence through the ros-mediated p16 pathway in human endothelial cells. Oncotarget. 2016;7:9634-44. https://doi. org/10.18632/oncotarget.7457.

57. Kyung UH, Kim E, Bae CD, Park J. TMAP/CKAP2 is essential for proper chromosome segregation. Cell Cycle. 2009;8:314-24. https://doi.org/10. 4161/cc.8.2.7597.

58. Zhang S, Wang Y, Chen S, Li J. Silencing of cytoskeleton-associated protein 2 represses cell proliferation and induces cell cycle arrest and cell apoptosis in osteosarcoma cells. Biomed Pharmacother. 2018;106:1396-403. https://doi.org/10.1016/j.biopha.2018.07.104.

59. Sawicki KT, Shang M, Wu R, Chang HC, Khechaduri A, Sato T, et al. Increased heme levels in the heart lead to exacerbated ischemic injury.
J Am Heart Assoc. 2015;4: e002272. https://doi.org/10.1161/JAHA.115. 002272.

60. Nie YH, Liu XD, Huang R, Xie DF, Yin WJ, Guan H, et al. Analysis of mRNA expression patterns in peripheral blood cells of 3 patients with cancer after the first fraction of $2 \mathrm{~Gy}$ irradiation: an integrated case report and systematic review. Dose Response. 2019. https://doi.org/10.1177/15593 25819833474.

61. Doğan A. Apelin receptor (Aplnr) signaling promotes fibroblast migration. Tissue Cell. 2019;56:98-106. https://doi.org/10.1016/j.tice.2019.01. 003.

62. Sawane M, Kidoya H, Muramatsu F, Takakura N, Kajiya K. Apelin attenuates UVB-induced edema and inflammation by promoting vessel function. Am J Pathol. 2011;179:2691-7. https://doi.org/10.1016/j.ajpath. 2011.08.024

63. Li C, He J, Zhong X, Gan H, Xia Y. CX3CL1/CX3CR1 axis contributes to angiotensin II-induced vascular smooth muscle cell proliferation and inflammatory cytokine production. Inflammation. 2018;41:824-34. https://doi.org/10.1007/s10753-018-0736-4

64. Golbus JR, Stitziel NO, Zhao W, Xue C, Farrall M, Mcpherson R, et al. Common and rare genetic variation in CCR2, CCR5, or CX3CR1 and risk of atherosclerotic coronary heart disease and glucometabolic traits. Circ Cardiovasc Genet. 2016;9:250-8. https://doi.org/10.1161/CIRCGENETI CS.115.001374.

65. Debo RJ, Lees CJ, Dugan GO, Caudell DL, Michalson KT, Hanbury DB, et al. Late effects of total-body gamma irradiation on cardiac structure and function in male rhesus macaques. Radiat Res. 2016;186:55-64. https://doi.org/10.1667/RR14357.1.

66. Farese AM, Cohen MV, Katz BP, Smith CP, Jackson W, Cohen DM, et al. A nonhuman primate model of the hematopoietic acute radiation syndrome plus medical management. Health Phys. 2012;103:367-82. https://doi.org/10.1097/HP.0b013e31825f75a7

67. Plett PA, Sampson CH, Chua HL, Joshi M, Booth C, Gough A, et al. Establishing a murine model of the hematopoietic syndrome of the acute radiation syndrome. Health Phys. 2012;103:343-55. https://doi.org/10. 1097/HP.0b013e3182667309.

68. Hall J, Jeggo PA, West C, Gomolka M, Quintens R, Badie C, et al. lonizing radiation biomarkers in epidemiological studies-an update. Mutat Res Mutat Res. 2017;771:59-84. https://doi.org/10.1016/j.mrrev.2017.01.001.

69. Coleman CN, Eke I, Makinde AY, Chopra S, Demaria S, Formenti SC, et al. Radiation-induced adaptive response: new potential for cancer treatment. Clin Cancer Res. 2020. https://doi.org/10.1158/1078-0432. ccr-20-0572.

70. Karimian A, Ahmadi Y, Yousefi B. Multiple functions of p21 in cell cycle, apoptosis and transcriptional regulation after DNA damage. DNA Repair. 2016;42:63-71. https://doi.org/10.1016/j.dnarep.2016.04.008.

71. Tsuchihara K, Lapin V, Bakal C, Okada H, Brown L, Hirota-Tsuchihara $M$, et al. Ckap2 regulates aneuploidy, cell cycling, and cell death in a p53-dependent manner. Cancer Res. 2005;65:6685-91. https://doi.org/ 10.1158/0008-5472.CAN-04-4223.

72. Sándor N, Schilling-Tóth B, Kis E, Benedek A, Lumniczky K, Sáfrány G, et al. Growth Differentiation Factor-15 (GDF-15) is a potential marker of radiation response and radiation sensitivity. Mutat Res Toxicol Environ Mutagen. 2015;793:142-9. https://doi.org/10.1016/j.mrgentox.2015.06. 009.

73. Rai R, Ghosh AK, Eren M, Mackie AR, Levine DC, Kim SY, et al. Downregulation of the apelinergic axis accelerates aging, whereas its systemic restoration improves the mammalian healthspan. Cell Rep. 2017;21:1471-80. https://doi.org/10.1016/j.celrep.2017.10.057.

74. Shyamasundar S, Ong C, Yung LYL, Dheen ST, Bay BH. miR-128 regulates genes associated with inflammation and fibrosis of rat kidney cells in vitro. Anat Rec. 2018;301:913-21. https://doi.org/10.1002/ar.23763.

75. Principe DR, Diaz AM, Torres C, Mangan RJ, DeCant B, McKinney R, et al. TGF $\beta$ engages MEKJERK to differentially regulate benign and malignant pancreas cell function. Oncogene. 2017;36:4336-48. https://doi.org/10. 1038/onc.2016.500.

76. Butz H, Likó I, Czirják S, Igaz P, Khan MM, Zivkovic V, et al. Downregulation of Wee1 kinase by a specific subset of microRNA in human sporadic pituitary adenomas. J Clin Endocrinol Metab. 2010. https://doi. org/10.1210/jc.2010-0581.

77. Perez-Añorve IX, Gonzalez-De la Rosa $\mathrm{CH}$, Soto-Reyes E, Beltran-Anaya FO, Del Moral-Hernandez O, Salgado-Albarran M, et al. New insights 
into radioresistance in breast cancer identify a dual function of miR-122 as a tumor suppressor and oncomiR. Mol Oncol. 2019;13:1249-67. https://doi.org/10.1002/1878-0261.12483.

78. Lang X, Green MD, Wang W, Yu J, Choi JE, Jiang L, et al. Radiotherapy and immunotherapy promote tumoral lipid oxidation and ferroptosis via synergistic repression of SLC7A11. Cancer Discov. 2019;9:1673-85. https://doi.org/10.1158/2159-8290.CD-19-0338.

79. Guard SE, Poss ZC, Ebmeier CC, Pagratis M, Simpson H, Taatjes DJ, et al. The nuclear interactome of DYRK1A reveals a functional role in DNA damage repair. Sci Rep. 2019;9:6539. https://doi.org/10.1038/ s41598-019-42990-5.

80. Xu XL, Jiang YH, Feng JG, Su D, Chen PC, Mao WM. MicroRNA-17, MicroRNA-18a, and MicroRNA-19a are prognostic indicators in esophageal squamous cell carcinoma. Ann Thorac Surg. 2014;97:1037-45. https:// doi.org/10.1016/j.athoracsur.2013.10.042.

81. Li L, Shi B, Chen J, Li C, Wang S, Wang Z, et al. An E2F1/MiR-17-92 negative feedback loop mediates proliferation of mouse palatal mesenchymal cells. Sci Rep. 2017. https://doi.org/10.1038/s41598-017-05479-7.

82. Sharma S, Munger K. Expression of the long noncoding RNA dino in human papillomavirus-positive cervical cancer cells reactivates the dormant TP53 tumor suppressor through ATM/CHK2 signaling. MBio. 2020;11:1-15. https://doi.org/10.1128/mBio.01190-20.

83. Shasha D, Harrison LB. Anemia treatment and the radiation oncologist: optimizing patient outcomes. Oncology. 2001;15:1486-91.

84. Rowinska Z, Koeppel TA, Sanati M, Schelzig H, Jankowski J, Weber C, et al. Role of the CX3C chemokine receptor CX3CR1 in the pathogenesis of atherosclerosis after aortic transplantation. PLoS ONE. 2017. https://doi.org/10.1371/journal.pone.0170644.

85. Krigsfeld GS, Sanzari JK, Kennedy AR. The effects of proton radiation on the prothrombin and partial thromboplastin times of irradiated ferrets. Int J Radiat Biol. 2012;88:327-34. https://doi.org/10.3109/09553002. 2012.652727.

86. Feng M, Normolle D, Pan CC, Dawson LA, Amarnath S, Ensminger WD, et al. Dosimetric analysis of radiation-induced gastric bleeding. Int J Radiat Oncol Biol Phys. 2012. https://doi.org/10.1016/j.jprobp.2012.02. 029.

87. Jackson IL, Gurung G, Poirier Y, Gopalakrishnan M, Cohen EP, SheaDonohue T, et al. A New Zealand white rabbit model of thrombocytopenia and coagulopathy following total body irradiation across the dose range to induce the hematopoietic-subsyndrome of acute radiation syndrome. Int J Radiat Biol. 2019. https://doi.org/10.1080/09553 002.2019.1668981.

88. Cannon MV, van Gilst WH, de Boer RA. Emerging role of liver X receptors in cardiac pathophysiology and heart failure. Basic Res Cardiol. 2016;111:1-17. https://doi.org/10.1007/s00395-015-0520-7.

89. Munetsuna E, Hojo Y, Hattori M, Ishii H, Kawato S, Ishida A, et al. Retinoic acid stimulates $17 \beta$-estradiol and testosterone synthesis in rat hippocampal slice cultures. Endocrinology. 2009;150:4260-9. https://doi. org/10.1210/en.2008-1644.

90. Francelle L, Galvan L, Gaillard MC, Petit F, Bernay B, Guillermier M, et al. The striatal long noncoding RNA Abhd1 1 os is neuroprotective against an N-terminal fragment of mutant huntingtin invivo. Neurobiol Aging. 2015;36:1601.e7-16. https://doi.org/10.1016/j.neurobiolaging.2014.11. 014.

91. Zhao Y, Cao F, Yu X, Chen C, Meng J, Zhong R, et al. Linc-RAM is required for FGF2 function in regulating myogenic cell differentiation. RNA Biol. 2018:15:404-12. https://doi.org/10.1080/15476286.2018.1431494.

92. Yu X, Zhang Y, Li T, Ma Z, Jia H, Chen Q, et al. Long non-coding RNA Linc-RAM enhances myogenic differentiation by interacting with MyoD. Nat Commun. 2017. https://doi.org/10.1038/ncomms 14016.

93. Megeney LA, Kablar B, Perry RLS, Ying C, May L, Rudnicki MA. Severe cardiomyopathy in mice lacking dystrophin and MyoD. Proc Natl Acad Sci USA. 1999;96:220-5. https://doi.org/10.1073/pnas.96.1.220.

94. Yu YH, Hu ZY, Li MH, Li B, Wang ZM, Chen SL. Cardiac hypertrophy is positively regulated by long non-coding RNA PVT1. Int J Clin Exp Pathol. 2015:8:2582-9.

95. Wu D, Li Y, Zhang H, Hu X. Knockdown of Lncrna PVT1 enhances radiosensitivity in non-small cell lung cancer by sponging miR-195. Cell Physiol Biochem. 2017;42:2453-66. https://doi.org/10.1159/000480209.

96. He Y, Jing $Y$, Wei F, Tang $Y$, Yang L, Luo J, et al. Long non-coding RNA PVT1 predicts poor prognosis and induces radioresistance by regulating DNA repair and cell apoptosis in nasopharyngeal carcinoma. Cell Death Dis. 2018. https://doi.org/10.1038/s41419-018-0265-y.

97. Zhao Y, Zhao J, Guo X, She J, Liu Y. Long non-coding RNA PVT1, A molecular sponge for miR-149, contributes aberrant metabolic dysfunction and inflammation in IL-1 $\beta$-simulated osteoarthritic chondrocytes. 2018. Biosci Rep. https://doi.org/10.1042/BSR20180576.

98. Zheng C, Xiao Y, Li Y, He D. Knockdown of long non-coding RNA PVT1 inhibits the proliferation of raji cells through cell cycle regulation. Oncol Lett. 2019;18:1225-34. https://doi.org/10.3892/ol.2019.10450.

99. Xiong X, Yuan J, Zhang N, Zheng Y, Liu J, Yang M. Silencing of IncRNA PVT1 by miR-214 inhibits the oncogenic GDF15 signaling and suppresses hepatocarcinogenesis. Biochem Biophys Res Commun. 2020;521:478-84. https://doi.org/10.1016/j.bbrc.2019.10.137.

100. Creemers EE, Van Rooij E. Function and therapeutic potential of noncoding RNAs in cardiac fibrosis. Circ Res. 2016;1 18:108-18. https://doi. org/10.1161/CIRCRESAHA.115.305242.

101. Thum T, Gross C, Fiedler J, Fischer T, Kissler S, Bussen M, et al. MicroRNA-21 contributes to myocardial disease by stimulating MAP kinase signalling in fibroblasts. Nature. 2008;456:980-4. https://doi.org/10. 1038/nature07511.

102. Lang N, Wang C, Zhao J, Shi F, Wu T, Cao H. Long non-coding RNA BCYRN1 promotes glycolysis and tumor progression by regulating the miR-149/PKM2 axis in non-small-cell lung cancer. Mol Med Rep. 2020;21:1509-16. https://doi.org/10.3892/mmr.2020.10944.

103. Kong Q, Qiu M. Long noncoding RNA SNHG15 promotes human breast cancer proliferation, migration and invasion by sponging miR-211-3p. Biochem Biophys Res Commun. 2018;495:1594-600. https://doi.org/10. 1016/j.bbrc.2017.12.013.

104. Quan J, Pan X, He T, Lin C, Lai Y, Chen P, et al. Tumor suppressor miR$211-5 p$ is associated with cellular migration, proliferation and apoptosis in renal cell carcinoma. Exp Ther Med. 2018;15:4019-28. https://doi.org/ 10.3892/etm.2018.5908

105. Xia ZY, Hoo Y, Xie PL, Tang SY, Luo XH, Liao EY, et al. Runx2/miR-3960/ miR-2861 positive feedback loop is responsible for osteogenic transdifferentiation of vascular smooth muscle cells. Biomed Res Int. 2015;2015: 624037. https://doi.org/10.1155/2015/624037.

106. Filopei J, Frishman W. Radiation-induced heart disease. Cardiol Rev. 2012;20:184-8. https://doi.org/10.1097/CRD.0b013e3182431c23.

107. Shen L, Li C, Zhang H, Qiu S, Fu T, Xu Y. Downregulation of miR-146a Contributes to cardiac dysfunction induced by the tyrosine kinase inhibitor sunitinib. Front Pharmacol. 2019. https://doi.org/10.3389/ fphar.2019.00914

108. Wang X, Song C, Zhou X, Han X, Li J, Wang Z, et al. Mitochondria associated microRNA expression profiling of heart failure. Biomed Res Int. 2017. https://doi.org/10.1155/2017/4042509.

109. Liang Y, Hou L, Li L, Li L, Zhu L, Wang Y, et al. Dichloroacetate restores colorectal cancer chemosensitivity through the p53/miR-149-3p/PDK2mediated glucose metabolic pathway. Oncogene. 2020;39:469-85. https://doi.org/10.1038/s41388-019-1035-8.

110. Zheng S, Guo S, Sun G, Shi Y, Wei Z, Tang Y, et al. Gain of metabolic benefit with ablation of miR-149-3p from subcutaneous adipose tissue in diet-induced obese mice. Mol Ther. 2019;18:194-203. https://doi.org/ 10.1016/j.omtn.2019.07.024.

111. Pettersen IKN, Tusubira D, Ashrafi H, Dyrstad SE, Hansen L, Liu XZ, et al. Upregulated PDK4 expression is a sensitive marker of increased fatty acid oxidation. Mitochondrion. 2019;49:97-110. https://doi.org/10. 1016/j.mito.2019.07.009.

112. Paredes F, Sheldon K, Lassègue B, Williams HC, Faidley EA, Benavides $\mathrm{GA}$, et al. Poldip2 is an oxygen-sensitive protein that controls PDH and aKGDH lipoylation and activation to support metabolic adaptation in hypoxia and cancer. Proc Natl Acad Sci USA. 2018;115:1789-94. https:// doi.org/10.1073/pnas.1720693115.

113. Wang C, Yuan Y, Wu J, Zhao Y, Gao X, Chen Y, et al. Plin5 deficiency exacerbates pressure overload-induced cardiac hypertrophy and heart failure by enhancing myocardial fatty acid oxidation and oxidative stress. Free Radic Biol Med. 2019;141:372-82. https://doi.org/10.1016/j. freeradbiomed.2019.07.006.

114. Ellis JM, Bowman CE, Wolfgang MJ. Metabolic and tissue-specific regulation of Acyl-CoA metabolism. PLoS ONE. 2015. https://doi.org/10. 1371/journal.pone.0116587. 
115. Franklin MP, Sathyanarayan A, Mashek DG. Acyl-CoA thioesterase 1 (ACOT1) regulates PPARa to couple fatty acid flux with oxidative capacity during fasting. Diabetes. 2017;66:2112-23. https://doi.org/10.2337/ db16-1519.

116. Xia C, Dong R, Chen C, Wang H, Wang DW. Cardiomyocyte specific expression of Acyl-coA thioesterase 1 attenuates sepsis induced cardiac dysfunction and mortality. Biochem Biophys Res Commun. 2015;468:533-40. https://doi.org/10.1016/j.bbrc.2015.10.078.

117. Chung KW, Lee EK, Lee MK, Oh GT, Yu BP, Chung HY. Impairment of PPARa and the fatty acid oxidation pathway aggravates renal fibrosis during aging. J Am Soc Nephrol. 2018;29:1223-37. https://doi.org/10. 1681/ASN.2017070802.

118. Wu CY, Satapati S, Gui W, Max Wynn R, Sharma G, Lou M, et al. A novel inhibitor of pyruvate dehydrogenase kinase stimulates myocardial carbohydrate oxidation in diet-induced obesity. J Biol Chem. 2018;293:9604-13. https://doi.org/10.1074/jbc.RA118.002838.

119. Sung MM, Das SK, Levasseur J, Byrne NJ, Fung D, Kim TT, et al. Resveratrol treatment of mice with pressure-overload-induced heart failure improves diastolic function and cardiac energy metabolism. Circ Heart Fail. 2015;8:128-37. https://doi.org/10.1161/CIRCHEARTFAILURE.114. 001677.

120. Chopra S, Moroni M, Martello S, Bylicky M, May J, Hritzo B, et al. Gene expression profiles from heart, lung and liver samples of total-bodyirradiated minipigs: implications for predicting radiation-induced tissue toxicity. Radiat Res. 2020;194:411-30. https://doi.org/10.1667/ RADE-20-00123.1.

121. Pchejetski D, Foussal C, Alfarano C, Lairez O, Calise D, Guilbeau-Frugier $C$, et al. Apelin prevents cardiac fibroblast activation and collagen production through inhibition of sphingosine kinase 1. Eur Heart J. 2012;33:2360-9. https://doi.org/10.1093/eurheartj/ehr389.
122. Goidescu CM, Vida-Simiti LA. The apelin-APJ system in the evolution of heart failure. Clujul Med. 2015;88:3-8. https://doi.org/10.15386/ cjmed-380.

123. Budworth H, Snijders AM, Marchetti F, Mannion B, Bhatnagar S, Kwoh $\mathrm{E}$, et al. DNA repair and cell cycle biomarkers of radiation exposure and inflammation stress in human blood. PLoS ONE. 2012;7: e48619. https:// doi.org/10.1371/journal.pone.0048619.

124. Ellisen LW, Ramsayer KD, Johannessen CM, Yang A, Beppu H, Minda K, et al. REDD1, a developmentally regulated transcriptional target of p63 and p53, links p63 to regulation of reactive oxygen species. Mol Cell. 2002;10:995-1005. https://doi.org/10.1016/S1097-2765(02)00706-2.

125. Drevytska T, Gonchar E, Okhai I, Lynnyk O, Mankovska I, Klionsky D, et al. The protective effect of Hif3a RNA interference and HIF-prolyl hydroxylase inhibition on cardiomyocytes under anoxia-reoxygenation. Life Sci. 2018;202:131-9. https://doi.org/10.1016/j.lfs.2018.04.021.

126. Laughlin GA, Barrett-Connor E, Criqui MH, Kritz-Silverstein D. The prospective association of serum insulin-like growth factor I (IGF-I) and IGF-binding protein-1 levels with all cause and cardiovascular disease mortality in older adults: The Rancho Bernardo Study. J Clin Endocrinol Metab. 2004;89:114-20. https://doi.org/10.1210/jc.2003-030967.

127. Filiano AN, Fathallah-Shaykh HM, Fiveash J, Gage J, Cantor A, Kharbanda $\mathrm{S}$, et al. Gene expression analysis in radiotherapy patients and C57BL/6 mice as a measure of exposure to ionizing radiation. Radiat Res. 2011. https://doi.org/10.1667/RR2419.1.

\section{Publisher's Note}

Springer Nature remains neutral with regard to jurisdictional claims in published maps and institutional affiliations.
Ready to submit your research? Choose BMC and benefit from:

- fast, convenient online submission

- thorough peer review by experienced researchers in your field

- rapid publication on acceptance

- support for research data, including large and complex data types

- gold Open Access which fosters wider collaboration and increased citations

- maximum visibility for your research: over 100M website views per year

At BMC, research is always in progress.

Learn more biomedcentral.com/submissions 